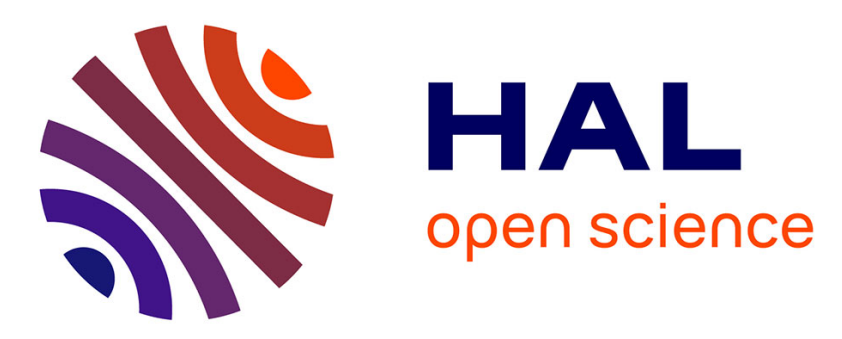

\title{
Low order modeling method for assessing the temperature of multi-perforated plates
}

\author{
Romain Bizzari, Dorian Lahbib, Antoine Dauptain, Florent Duchaine,
} Stéphane Richard, Franck Nicoud

\section{> To cite this version:}

Romain Bizzari, Dorian Lahbib, Antoine Dauptain, Florent Duchaine, Stéphane Richard, et al.. Low order modeling method for assessing the temperature of multi-perforated plates. International Journal of Heat and Mass Transfer, 2018, 127, pp.727-742. 10.1016/j.ijheatmasstransfer.2018.07.059 . hal02049164

\section{HAL Id: hal-02049164 \\ https://hal.science/hal-02049164}

Submitted on 26 Feb 2019

HAL is a multi-disciplinary open access archive for the deposit and dissemination of scientific research documents, whether they are published or not. The documents may come from teaching and research institutions in France or abroad, or from public or private research centers.
L'archive ouverte pluridisciplinaire HAL, est destinée au dépôt et à la diffusion de documents scientifiques de niveau recherche, publiés ou non, émanant des établissements d'enseignement et de recherche français ou étrangers, des laboratoires publics ou privés. 


\title{
Low order modeling method for assessing the temperature of multi-perforated plates
}

\author{
Romain Bizzari ${ }^{\mathrm{a}, *}$, Dorian Lahbib ${ }^{\mathrm{a}, \mathrm{b}}$, Antoine Dauptain ${ }^{\mathrm{a}}$, Florent Duchaine ${ }^{\mathrm{a}}$, Stephane Richard ${ }^{\mathrm{b}}$, \\ Franck Nicoud ${ }^{\mathrm{C}}$ \\ ${ }^{a}$ CERFACS - 42, Av. Gaspard Coriolis, 31057 Toulouse cedex 1, France \\ ${ }^{\mathrm{b}}$ Safran Helicopter Engines - Avenue Joseph Szydlowski, 64510 Bordes, France \\ ${ }^{\mathrm{C}}$ IMAG, Univ. Montpellier, CNRS, Montpellier, France
}

\section{A R T I C L E I N F O}

\section{Article history:}

Received 21 January 2018

Received in revised form 1 June 2018

Accepted 10 July 2018

Available online 30 July 2018

\section{Keywords:}

Effusion cooling

Conjugate heat transfer

Large-Eddy simulations

Adiabatic computations

Coupled computation

Modeling

\begin{abstract}
A B S T R A C T
A low-order model is proposed to predict the temperature of a multi-perforated plate from an unresolved adiabatic computation. Its development relies on the analysis of both an adiabatic and a conjugate heat transfer wall resolved large eddy simulation of an academic multi-perforated liner representative of the cooling systems used in combustion chambers of actual aero-engines. These two simulations show that the time averaged velocity field is marginally modified by the coupling with the heat diffusion in the perforated plate when compared to the adiabatic case. This gives rise to a methodology to assess the wall temperature from an unresolved adiabatic computation. It relies on heat transfer coefficients from referenced correlations as well as a mixing temperature relevant to the flow in the injection region where the cold micro-jets mix with the hot outer flow. In this approach, a coarse mesh simulation using an homogeneous adiabatic model for the aerodynamics of the flow with effusion is post-processed to provide a low cost alternative to conjugate heat transfer computations based on hole resolved meshes. The model is validated on an academic test case and successfully applied to a real industrial combustion chamber.
\end{abstract}

\section{Introduction}

To improve gas turbines efficiency, aeronautical engines manufacturers increase both the compressor pressure ratio and the turbine inlet temperature. A direct consequence is the increase of the thermal constraints imposed to the walls of the combustion chamber. Since the typical materials used in combustors cannot sustain more than $1100-1200 \mathrm{~K}$ before melting, controlling the temperature of the solid boundaries without compromising the overall efficiency of the engine is a critical issue. In modern combustors, effusion cooling [41] is often used to control the temperature of the walls surrounding the flame tube (see Fig. 1).

The casing being at a higher pressure than the flame tube, a micro-jet is formed at each aperture of the multi-perforated plate. The coalescence of these micro-jets induces a film region where the hot gases from the combustion chamber side mix with the fresh air from the casing. A sketch which displays the principle of effusion and important parameters is given in Fig. 2.

\footnotetext{
* Corresponding author.

E-mail address: bizzari@cerfacs.fr (R. Bizzari).
}

The general problem in cooling systems is to predict, for a given geometry and operating point, the coolant mass flow rate necessary to maintain the temperature of the plate below a critical value. The efficiency of this system is driven by many parameters (jet-to-jet distance, perforation arrangement, hole shape, size and inclination). In order to quantify the effect of these parameters, many arrangements have been studied in the literature. It has been shown that staggered inclined perforations offer a better protection than in line inclined perforations [51,40,18,31]. Also the optimal lateral $(\Delta x)$ and spanwise $(\Delta z)$ hole distances have been found $[46,65,59]$ in the range $4 d-8 d$, where $d$ is the hole diameter. From the distances between holes $(\Delta x, \Delta z)$ and the diameter of the aperture $(d)$ reported in Fig. 3, the plate porosity $\sigma$ can be computed. It represents the ratio between the perforated surface and the total surface of the plate:

$$
\sigma=\frac{\pi d^{2}}{4 \sin (\alpha)} \frac{1}{\Delta x \Delta z}
$$

where $\alpha$ shown in Figs. 2 and 3, is the angle between the streamwise and the perforation directions. 


\section{Nomenclature}

$\Delta x \quad$ streamwise pitch $[\mathrm{m}]$

$\Delta z \quad$ spanwise pitch $[\mathrm{m}]$

$C_{P} \quad$ specific heat capacity of the plate $[\mathrm{J} / \mathrm{K} / \mathrm{kg}]$

$d \quad$ diameter of the aperture $[\mathrm{m}]$

$D_{R} \quad$ density ratio [-]

$J \quad$ momentum ratio [-]

$L \quad$ perforation length [m]

$M \quad$ blowing ratio [-]

$\mathrm{Nu} \quad$ Nusselt number [-]

Pr Prandlt number [-]

$q \quad$ heat flux $\left[\mathrm{W} \mathrm{m}^{-2}\right]$

Re Reynolds number [-]

$S_{t} \quad$ Stanton number [-]

$T \quad$ temperature $[\mathrm{K}]$

Greeks

injection angle $\left[{ }^{\circ}\right]$ effectiveness [-]

$\begin{array}{ll}\eta_{\text {ad }} & \text { adiabatic effectiveness [-] } \\ \lambda & \text { thermal conductivity }\left[\mathrm{W} \mathrm{m} \mathrm{m}^{-1} \mathrm{~K}^{-1}\right] \\ \Phi & \text { global heat flux }\left[\mathrm{W} \mathrm{m} \mathrm{m}^{-2}\right] \\ \rho & \text { density }\left[\mathrm{kg} \mathrm{m}^{-3}\right] \\ \sigma & \text { porosity [-] } \\ \Theta & \text { non dimensional temperature divided by the adiabatic } \\ & \text { temperature [-] } \\ \theta & \text { non dimensional temperature [-] } \\ \text { Acronyms } & \\ \text { CFD } & \text { Computational Fluid Dynamics } \\ \text { CHT } & \text { Conjugate Heat Transfer } \\ \text { CPU } & \text { Central Processor Unit } \\ \text { LES } & \text { Large Eddy Simulation } \\ \text { RANS } & \text { Reynolds Averaged Navier Stokes }\end{array}$

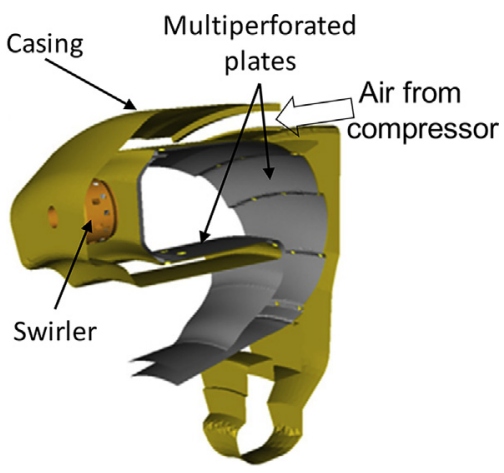

Fig. 1. Sector of an annular helicopter combustion chamber taking into account the swirler, the flame tube and the chamber casing. Extracted from [28].

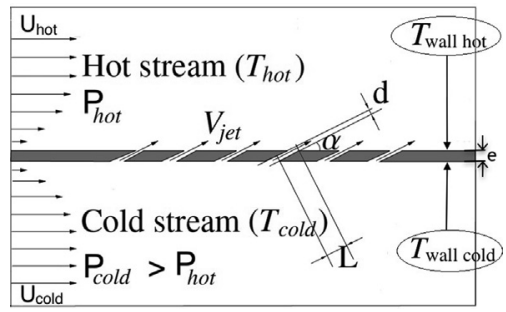

Fig. 2. Schematic view of a multi-perforated plate which separates the combustion chamber (hot gases) from the casing (cold gases) presented on Fig. 1.

As for the classical jet-in-cross flow configurations [61], the flow regime around a multi-perforated plate is piloted by the blowing $(\mathrm{M})$ and the momentum $(\mathrm{J})$ ratios defined as:

$$
\begin{gathered}
M=\frac{\rho_{\text {jet }} V_{\text {jet }}}{\rho_{\text {hot }} U_{\text {hot }}}, \\
J=\frac{\rho_{\text {jet }} V_{\text {jet }}^{2}}{\rho_{\text {hot }} U_{\text {hot }}^{2}},
\end{gathered}
$$

where $\rho_{\text {jet }}$ and $V_{\text {jet }}$ denote the jet density and the jet velocity respectively while $\rho_{\text {hot }}$ is the density of the hot gases in the combustion

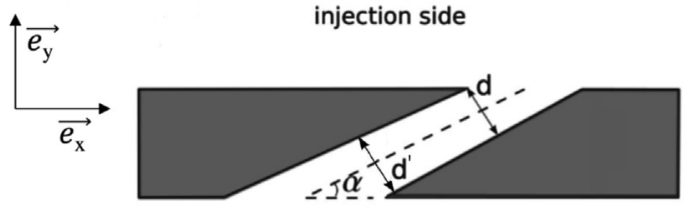

(a)

suction side

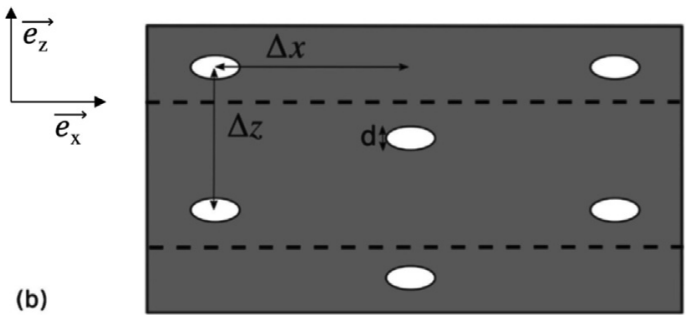

Fig. 3. (a) Detailed side view of the perforation, (b) top view of the plate with the periodic domain calculated (dotted).

chamber and $U_{h o t}$ is the streamwise velocity of the hot gases (see Fig. 2).

Ammari et al. [1] underlined that $\mathrm{M}$ and $\mathrm{J}$ also impact the heat fluxes through the density ratio $D_{R}$ defined as:

$$
D_{R}=M^{2} / J=\frac{\rho_{\text {jet }}}{\rho_{\text {hot }}} .
$$

Gustafsson [30] showed that the Mach number does not play a significant role on the cooling effectiveness at least in the flow regimes characteristic of typical industrial applications. Eriksen and Goldstein [22] and Champion [13] drew the same conclusion for the Reynolds number of the injection flow. Therefore, when comparing the efficiency of multi-perforated cooling systems, the operating point is suitably defined once $\mathrm{M}$ and $\mathrm{J}$ have been selected.

The cooling effectiveness $\eta$ is a non-dimensional quantity usually introduced to characterize the thermal efficiency of effusion [45]; it is defined as:

$$
\eta=\frac{T_{\text {hot }}-T_{\text {wallhot }}}{T_{\text {hot }}-T_{\text {cold }}}
$$


where $T_{\text {hot }}, T_{\text {cold }}$ and $T_{\text {wallhot }}$ stand for the temperature of the fluid at the injection side (combustion chamber), at the suction side (casing) and of the plate on the hot side, respectively (see Fig. 2). To better characterize the mixing phenomenon in the fluid domain without the effect of conjugate heat transfer which modifies $T_{\text {wallhot }}$, the adiabatic cooling effectiveness $\eta_{a d}$ is also often introduced:

$$
\eta_{a d}=\frac{T_{\text {hot }}-T_{\text {adhot }}}{T_{\text {hot }}-T_{\text {cold }}},
$$

where $T_{\text {adhot }}$ is the wall temperature on the injection side for a nonconducting plate. From a practical point of view, $\eta_{a d}$ can be assessed numerically by using adiabatic thermal condition on the solid boundary and experimentally by using either a low conductivity plate (in order to minimize the heat exchange between the fluid and solid domains) or by measuring the concentration of a passive scalar introduced from the casing side [32].

Table 1 gathers dynamic and geometrical parameters from the most relevant experimental and numerical studies of effusion; the type of variable investigated are also reported. Most of the previous studies have been performed either at low or at moderate blowing and momentum ratios. It should be noted, however, that multi-perforated plates in real combustion chambers operate at larger injection rate, with $\mathrm{M}$ and $\mathrm{J}$ of order 5-20 and 30-90, respectively. One reason for this mismatch is that many studies rely on upscaled geometries to ease measurements. Operating at lower injection rate obviously modifies the characteristics of the effusion flow, especially in the injection region. It may also have consequences regarding the thermal equilibrium of the plate by modifying the mixing between cold and hot gas as well as the relative strengths of the conduction (exchange through the solid plate) and the convection (fluid going through the holes) heat transfers. According to Cottin [17], the heat flux transmitted by conduction within the hole is as large as $37 \%$ of the total heat flux (convection and conduction) in the case of the LARA experiment of Miron [53] where $\mathrm{M}=3.6$ and $\mathrm{J}=13$; on the contrary, Florenciano [25] found that it was only $8 \%$ of the total heat flux in a flow regime corresponding to $\mathrm{M}=8.4$ and $\mathrm{J}=31$.
When numerically computing an entire combustion chamber, these cooling systems have to be considered. On the one hand, the size of an engine is about one meter, on the other hand, multiperforated holes have a diameter of half a millimeter. Thus, regarding the actual computational resources, it is impossible to resolve the flow scales involved and orifices have to be modeled. In order to understand the physics of the flow, Mendez and Nicoud [50] performed a wall resolved Large Eddy Simulation (LES) of a biperiodic plate with effusion. This database allowed to show that the viscous terms, including the classical wall shear stress $\tau_{w}$, are small compared to the inviscid flux of longitudinal momentum, $\rho U V$, through the holes. This result disqualifies any attempt to represent effusion flow with a (modified) logarithmic law based on classical wall units where the friction velocity $\sqrt{\tau_{w} / \rho}$ would be the characteristic velocity. Instead, further analyzing the numerical database [50], Mendez and Nicoud [49] proposed an homogeneous adiabatic model able to represent the effect of effusion on the boundary layer structure. In this view, the multi-perforated plate is modeled as a uniform boundary so that meshes far too coarse to represent the holes can still be used. The homogeneous model [49] is now commonly used in full scale computations of combustors with perforated liners as mentioned in the review of Savary et al. [63]. However, since this boundary condition is adiabatic, it gives no insight on the wall heat flux. To handle it, an analytical 1D models have been first proposed in the literature to assess wall film cooling for flat walls [44,29]. Making use of increasing computational power, Andreini et al. [6] proposed a method to study heat transfer on complex geometries, which relies on porous boundary condition to model the fluid behaviors. To assess the heat transfer coefficient and the convective temperature, two computations are needed. A first one with adiabatic boundary conditions allows to assess the convective temperature thanks to a flux balance. A second flux balance from a computation with isothermal boundary conditions gives the heat transfer coefficient. To better account for the heat transfer between fluid and solid, Voigt et al. [68] proposed a point mass source model which allows to perform a conjugate heat transfer (CHT) simulation without dealing with the effusion pipe. Since the pipe is modeled by a mass source

\section{Table 1}

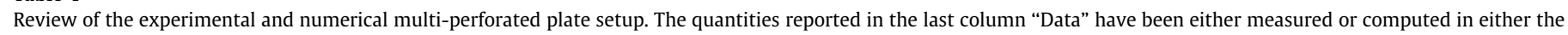
injection side or the whole fluid domain as depicted in column "Regions". The subscript "ad" refers to adiabatic values.

\begin{tabular}{|c|c|c|c|c|c|}
\hline Reference & $\mathrm{M} / \mathrm{J}$ & Rows & $\alpha$ & Regions & Data \\
\hline \multicolumn{6}{|c|}{ Experimental setup } \\
\hline Leger et al. [42] & $1-3 / 7-12$ & $9-35$ & 60 & Injection & $\mathrm{T}, \eta$ \\
\hline Andreini et al. [6] & $7.2 / 16$ & 21 & 60 & Injection & $\vec{V}, \mathrm{~T}, \eta$ \\
\hline Miron et al. [53] & $3.6 / 13$ & 12 & 30 & Injection & $\vec{V}$ \\
\hline Michel et al. [52] & $8.8 / 77.4$ & 9 & 60 & Injection & $\vec{V}$ \\
\hline Scrittore et al. [64] & $3.2-5 / 12-27$ & 30 & 60 & Injection & $\vec{V}, \eta_{a d}$ \\
\hline Zhong and Brown [69] & $0.4 / 0.1$ & 12 & 90 & All & $\vec{V}, \mathrm{~T}, \eta, \eta_{a d}$ \\
\hline Andreini et al. [9] & $0.5-5 / 0.2-25$ & $14-22$ & 30,90 & Injection & $\eta_{a d}, \eta$ \\
\hline Jonhson et al. [35] & $0.4-1.7 / 0.17-0.94$ & 3 & 30 & Injection & $\eta_{a d}, \eta$ \\
\hline Kakade et al. [36] & $0.47-2 / 0.15-4.12$ & 6 & 20 & Injection & $U, \eta_{a d}, \eta$ \\
\hline Martiny et al. [43] & $0.5-3 / 0.14-5.3$ & 8 & 17 & Injection & $\eta_{a d}, \eta$ \\
\hline Andreini et al. [4] & $0.8-4.5 / 0.6-20$ & 23 & $20,30,90$ & Injection & $\eta_{a d}$ \\
\hline Andreini et al. [5] & $1.5-7 / 1.3-49$ & 29 & 30 & Injection & $\eta_{a d}, \eta$ \\
\hline \multicolumn{6}{|c|}{ Numerical setup } \\
\hline Most [54] & $1.3-2.3 / 1.8-4.6$ & 12 & 60 & Injection & $\vec{V}$ \\
\hline Harrington et al. [33] & $0.4 / 0.8$ & 10 & 90 & Injection & $T_{a d}, \vec{V}, \eta_{a d}$ \\
\hline Errera and Chemin [23] & $1.2 / 0.5$ & 12 & 45 & All & $\mathrm{T}$ \\
\hline Mendez and Nicoud [50] & $1.5 / 2.25$ & $\infty$ & 30 & All & $\vec{V}$ \\
\hline Zhong and Brown [70] & $0.4 / 0.1$ & 12 & 90 & All & $\mathrm{T}, \eta, \eta_{a d}$ \\
\hline Cottin [17] & $3.2-8.5 / 3.1-21.7$ & 15 & 30 & All & $\mathrm{T}, \eta$ \\
\hline Florenciano $[25]$ & $8.4 / 31$ & 12 & 28 & All & $\mathrm{T}$ \\
\hline Florenciano and Bruel [24] & $8.0 / 29$ & 12 & 30 & All & $\mathrm{T}, \eta, \eta_{a d}$ \\
\hline Andrei et al. [3] & $1-3 / 0.6-9$ & 18 & 30,90 & Injection & $\eta_{a d}$ \\
\hline
\end{tabular}


and a mass sink it drastically reduces the computational cost. Andreini et al. [7] proposed an improvement of this model thanks to a local pressure drop formulation allowing the automatic calculation of the mass flow. This method was implemented in a RANS solver (ANSYS CFX) and gives satisfactory results as demonstrated in Andreini et al. [8]. In recent studies, effects of radiation have also been introduced. Mazzei et al. [48] used a 3 solvers coupling approach to account for the interplay between fluid mechanics; solid heat diffusion and radiative transfers. Berger et al. [10] used the same methodology but solved the fluid dynamics with a LES solver. In this case, effusion holes was modeled with the homogeneous model from Mendez and Nicoud [49] and the first node temperature was taken as a surrogate of the adiabatic reference temperature in order to compute the exchanged heat flux.

Florenciano and Bruel [24] have compared the output of several correlations for heat transfer coefficients $\left(h\left[\mathrm{~W} \mathrm{~m}{ }^{-2} \mathrm{~K}^{-1}\right]\right)$ with respect to a fully coupled, holes resolved simulation where both the fluid and solid domains were accounted for. Heat transfer coefficients are often used to represent the wall heat flux $\Phi$ thanks to the Newton relation $\Phi=h\left(T_{\text {ref }}-T_{\text {wall }}\right)$ and are expressed through correlations based on non-dimensional numbers. Regarding effusion flows, Cottin [17] proposed for the injection side:

$$
h_{\text {hot }}=\rho_{\text {hot }} C_{p, h o t} U_{\text {hot }} S_{t},
$$

with the Stanton number approximated by:

$$
S_{t}=0.00675\left(\frac{V_{\text {jet }}}{U_{\text {hot }}}\right)^{0.67}\left(\frac{\rho_{\text {jet }}}{\rho_{\text {hot }}}\right)^{1.22},
$$

with $C_{p, h o t}$ the specific heat capacity of the air in the hot side and $S_{t}$ the Stanton number. Florenciano and Bruel [24] proposed another expression to evaluate the Stanton number which better fits the results when dealing with high momentum and blowing ratios flows $(M \approx 8$ and $J \approx 30)$ :

$$
S_{t}=0.00241\left(\frac{V_{\text {jet }}}{U_{\text {hot }}}\right)^{0.67}\left(\frac{\rho_{\text {jet }}}{\rho_{\text {hot }}}\right)^{1.22} .
$$

Cottin [17] also proposed correlations to assess the Nusselt number for the suction side (Eq. (10)) and the hole's inner surface (Eq. (11)):

$$
\begin{aligned}
& N_{u, \text { cold }}=0.023 \operatorname{Re}_{D h}^{0.8} \operatorname{Pr}^{0.33}\left(1+0.5 \frac{V_{\text {jet }}}{U_{\text {cold }}}\right)^{0.77} \\
& N_{u, \text { hole }}=0.02775 \operatorname{Re}_{d}^{0.8}\left(\operatorname{Re}_{d}^{0.17}\left(\frac{L}{d}\right)^{-0.8}\right)^{0.275} .
\end{aligned}
$$

The Reynolds number $\left(R e_{D h}\right)$ used to compute the Nusselt number on the cold side is based on the hydraulic diameter (twice the channel height) and the bulk velocity [14,24]. Pr denotes the Prandlt number. The Nusselt number into the holes takes into account the aspect ratio $L / d$ (i.e. the perforation length-to-hole diameter ratio) and the Reynolds number based on the hole diameter [24]. Using these Nusselt numbers, heat transfer coefficients can then be recovered using the relation $h=N_{u} \lambda_{f} / L_{\text {ref }}$, with $\lambda_{f}$ the thermal conductivity of the fluid and $L_{\text {ref }}$ a characteristic length. Florenciano and Bruel [24] proposed to take as characteristic length the average of the minor and major axis of the ellipse in the middle section of the hole. Assuming that appropriate expressions for the heat transfer coefficients are available for the suction $\left(h_{\text {cold }}\right)$, the injection sides $\left(h_{\text {hot }}\right)$ and the inner hole of the plate $\left(h_{\text {hole }}\right)$, the corresponding heat fluxes can then be computed from $\Phi_{\text {cold }}=h_{\text {cold }}\left(T_{\text {refcold }}-T_{\text {wallcold }}\right)$, $\Phi_{\text {hot }}=h_{\text {hot }}\left(T_{\text {refhot }}-T_{\text {wallhot }}\right)$ and $\Phi_{\text {hole }}=h_{\text {hole }}\left(T_{\text {refhole }}-T_{\text {wallhole }}\right)$ respectively. As the Biot number of the plate is very small $\left(B_{i}<10^{-2}\right.$ in [24]), the temperature variations across the plate thickness can be neglected. Then, balancing the three heat fluxes at steady state allows computing the wall temperature $T_{\text {wall }}$ (see Section 6 for details). However the values of $T_{\text {ref }}$ have to be determined on both sides and into the holes. Note that the same conclusion was drawn by Grenard and Scherrer [29]. Such quantity is not trivial to assess since the temperature on the hot side results from the mixing between the cold jets and the cross flow of hot gases.

Using an unresolved adiabatic LES computation with homogeneous model for the aerodynamics [49] combined with an estimator to get the reference temperature would be a significant step towards the assessment of liners temperature in realistic combustion chambers and would open new perspectives in terms of design and optimization of aero engines. Indeed, this method would not require a coupled computation which is an important saving in terms of CPU cost.

The aim of this study is to derive a methodology to assess the reference temperature in LES of a combustion chamber where multiperforated wall are treated with an homogeneous adiabatic model. To achieve this objective, the numerical database of Florenciano and Bruel [24] is first extended in Section 3 after the initial set up has been recalled in Section 2. In Section 4, coupled and adiabatic simulations are analyzed before an energy balance is proposed in Section 5 to support the new modeling assumptions. Three estimators of the reference wall temperature $T_{\text {refhot }}$ are proposed and tested a priori in Section 6. The same estimators are used together with the Mendez and Nicoud [49] homogeneous model and correlations in order to demonstrate how the wall temperature can be assessed at low CPU cost compared to a wall resolved simulation. The efficiency of the estimator is demonstrated in Section 7 on a test case extracted from Andrei et al. [3]. Finally, in order to illustrate the capacity of the approach to deal with complex flows, it is applied to an industrial configuration in Section 8 and compared to experimental results from thermocolor tests.

\section{Flow configuration}

The geometry of the present study, denoted MAVERIC- $\mathrm{H}$, is inspired from the MAVERIC set up built and studied by Petre et al. [58], Miron [53] and Florenciano [25]. It consists of two parallel channels communicating through 144 converging holes disposed in 12 staggered rows as shown in Fig. 4 and described in $[38,11]$.

The flow solver used in this paper (see Section 3.1) was chosen to compute the MAVERIC test rig by Motheau et al. [55] and a satisfactory comparison with the experimental data was obtained. Due to experimental constraints, the holes in the MAVERIC setup were upscaled (12.5:1) compared to typical apertures of perforated liners used in combustors. The numerical MAVERIC-H setup recovers the actual hole diameter of $0.4 \mathrm{~mm}$ and aims at reproducing

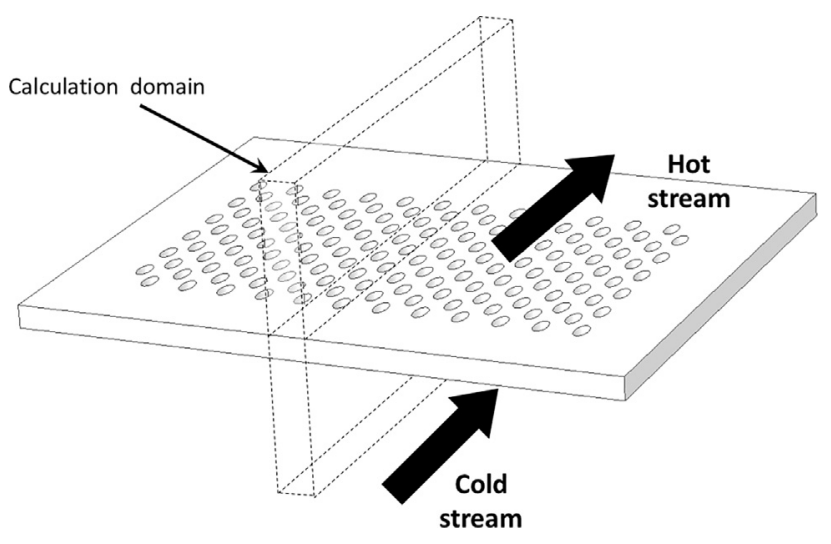

Fig. 4. Computational domain. 
Table 2

Main characteristics of the MAVERIC-H configuration. All the geometrical parameters are the same as for the set up considered in Florenciano and Bruel [12] except that $d=0.4 \mathrm{~mm}$ instead of $d=5 \mathrm{~mm}$ in [12]. The flow regime ( $\mathrm{M}$ and $\mathrm{J}$ values) is representative of an actual aero-engine.

\begin{tabular}{lccccc}
\hline \multicolumn{1}{c}{ Diameters $(\mathrm{mm})$} & Porosity $\sigma$ & Angle $\alpha$ & Thickness e & $\Delta x$ & $\Delta z$ \\
\hline$d=0.4, d^{\prime}=1.33 d$ & $4.09 \times 10^{-2}$ & $27.5^{\circ}$ & $2 d$ & $5.84 d$ & $6.74 d$ \\
$\mathrm{M}$ & $\mathrm{J}$ & \multicolumn{2}{c}{ Re } & & Mach \\
\hline 8.4 & 31 & \multicolumn{2}{c}{2700} & 0.26 \\
\hline
\end{tabular}

Table 3

Thermo physical properties of the plate.

\begin{tabular}{cc}
\hline Density $\rho$ & $7900 \mathrm{~kg} \mathrm{~m}^{-3}$ \\
Conductivity $\lambda_{S}(T)$ & $5.96+0.017 \times T$ W m $\mathrm{K}^{-1} \mathrm{~K}^{-1}$ \\
Heat capacity $C_{P}$ & $586 \mathrm{~J} \mathrm{~kg}^{-1} \mathrm{~K}^{-1}$ \\
\hline
\end{tabular}

geometrical and operating conditions more representative of real combustor liners than other database available in the literature. All the geometric parameters of the plate are given in Table 2.

The hot and cold channels are 114.25d long, $H=24 d$ high and $6.74 d$ wide. The perforation length is about $4.3 d$, a typical value for liners in combustion chambers. Note also that the apertures are slightly conical (convergent) with $d^{\prime}=1.33 d$ (see Fig. 3 ). The pressure of the hot flow is about $0.445 \mathrm{MPa}$ and the temperature equals $1580 \mathrm{~K}$, while it is $667 \mathrm{~K}$ on the cold side. The mean hot flow velocity at the inlet, $U_{\text {hot }}$ is $25 \mathrm{~m} \mathrm{~s}^{-1}$ whereas it is $U_{\text {cold }}=50 \mathrm{~m} \mathrm{~s}^{-1}$ for the cold side. The mass flow rate across the plate is controlled by the pressure difference between the two channels, which is about $3 \%$ of the injection side pressure $(\Delta P=13,327 \mathrm{~Pa})$. The working fluid is air. These conditions lead to blowing and momentum ratios equals to $M=8.4$ and $J=31$ respectively. The resulting Reynolds (based on the aperture diameter and bulk velocity) and Mach numbers within the perforations (averaged over the twelve rows) are 2700 and 0.26 , respectively. The main physical properties of the material used (KCN22W) for the plate itself are given in Table 3.

The computational domains used in this study are depicted in Fig. 5. To ease the reproduction of the calculation and because turbulent fluctuations in the main flow play a minor role for the investigated flow regime [22,13], no turbulent fluctuations were prescribed at the inlet boundaries. Still, the velocity profiles were set with a power law based on the Reynolds number as appropriate for turbulent flows. For the hot side, the inlet velocity is defined as:

$$
U_{\text {hot }}=30\left(1-\left(\frac{\left|y_{c h}-y\right|}{0.5 H}\right)^{5}\right)
$$

where $y_{c h}$ is the y coordinate of the hot channel center and $H$ his height.

The inlet velocity on the cold side is defined as:

$$
U_{\text {cold }}=57.8\left(1-\left(\frac{\left|y_{c c}-y\right|}{0.5 H}\right)^{6.4}\right)
$$

where $y_{c c}$ is the y coordinate of the cold channel center and $H$ his height.

To save computational time and because side effects have no influence on the flow at the center, only one hole per rows have

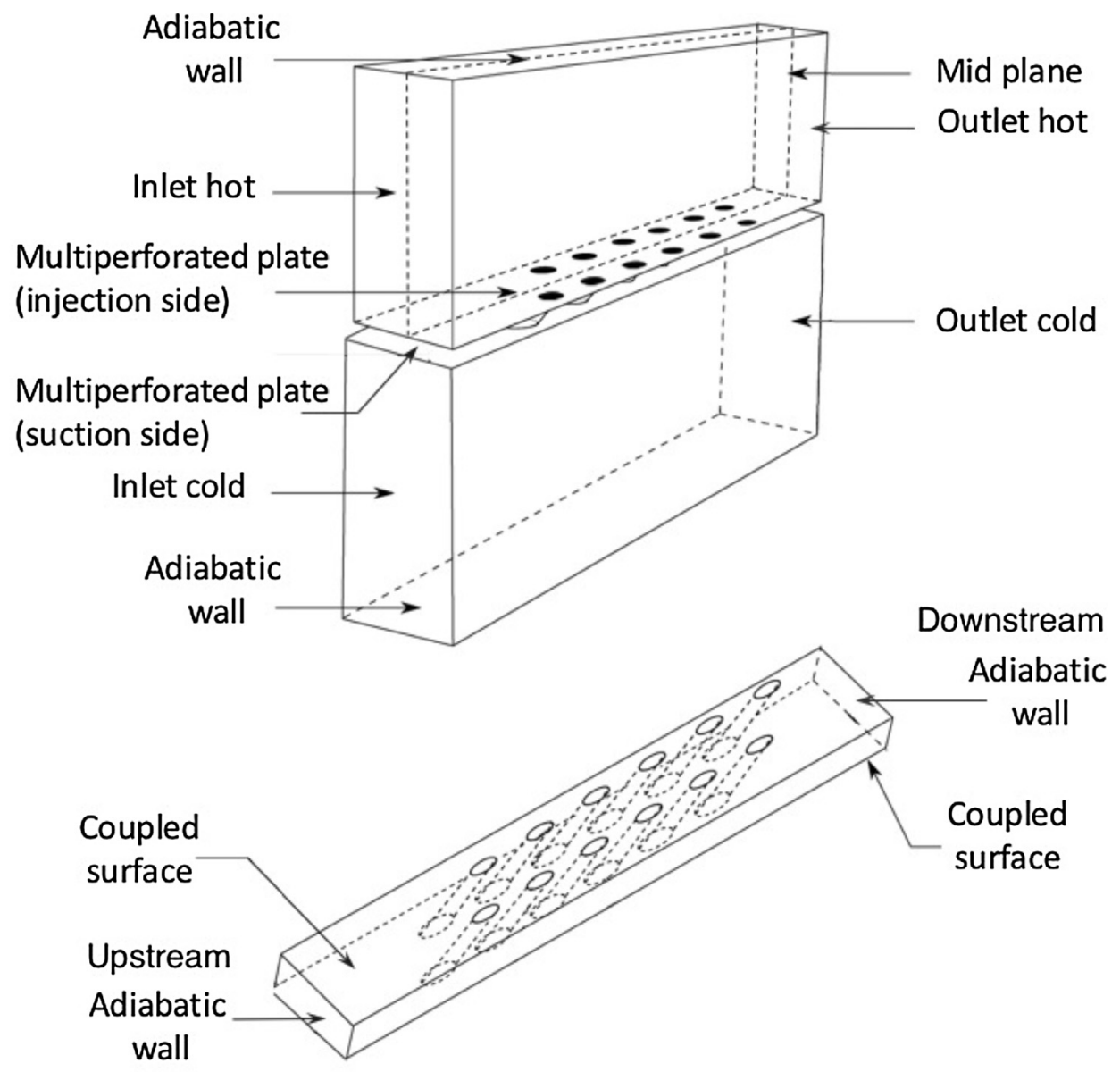

Fig. 5. Fluid (top) and solid (bottom) computational domains and boundary conditions used in the MAVERIC-H numerical setup. 
been computed (instead of 12 in the experiment) making a total of 12 holes in the simulation out of 144 in the experiment. Periodic conditions have been used in the spanwise direction to properly reproduce the staggered arrangement and jets interactions. The upper and lower walls of the hot and cold channels are both considered adiabatic (Fig. 5). For the boundary interfaces between the flow domain and the multi-perforated plate, a no slip condition is applied on the cold and hot sides of the plate as well as within the apertures. The thermal condition is either adiabatic for fluid standalone simulation or temperature imposed when both the fluid and solid domains are coupled. In the latter case, the heat flux computed from the fluid side is used as a boundary condition for the solid domain where the unsteady heat equation is solved. In both cases, adiabatic wall conditions are prescribed at the downstream and upstream solid faces (Fig. 5).

\section{Numerical methods}

Three simulations whose main characteristics are given in Table 4 have been performed:

- a coupled simulation denoted "resolved coupled" where the holes are explicitly represented together with both the suction and injection sides; both the flow equations (in the fluid domain) and the heat equation (in the solid domain) are solved;

- another hole resolved computation for the fluid domain where only adiabatic conditions are used at the multi-perforated plate surfaces and denoted "resolved adiabatic";

- an unresolved simulation, denoted "unresolved", where the multi-perforated plate is represented thanks to the adiabatic homogeneous model of Mendez and Nicoud [49]. In this case, only the injection side is computed, the holes and the casing being represented by the boundary condition provided by the homogeneous model.

Accordingly, two meshes have been used for the fluid domain, a resolved one (approximatively $5 \times 10^{7}$ tetrahedral cells) to perform holes resolved simulations, and a coarse one (approximatively $3 \times 10^{6}$ tetrahedral cells) which is well adapted to computations where the multi-perforated plate is represented by an homogeneous model. The mesh used for holes resolved computations is such that the number of cells per aperture diameter is at least 25 in the injection side (more in the suction side due to the conical shape of the holes, see Fig. 3 ). In wall units $\left(y^{+}\right)$, the first off wall point distance is less than 12 in the aperture and of the order of 5-6 elsewhere. In the solid domain (used only for the resolved coupled simulation), the mesh contains $5 \times 10^{6}$ tetrahedral cells which are slightly smaller than the fluid cells near the interface for coupling interpolation purposes.

\subsection{Numerical tools}

The two solvers used in this study are described in the present section.

Table 4

Summary of the simulations performed. In the resolved coupled case, two meshes were used, one for the fluid and one for the solid. For the unresolved simulation, multi-perforations are modeled with homogeneous model [49].

\begin{tabular}{cccc}
\hline & Fluid cells mesh & Solid cells mesh & Modeling \\
\hline Resolved coupled & $5 \times 10^{7}$ & $5 \times 10^{6}$ & N/A \\
Resolved adiabatic & $5 \times 10^{7}$ & N/A & N/A \\
Unresolved & $3 \times 10^{6}$ & N/A & Homogeneous \\
\hline
\end{tabular}

\subsubsection{The fluid solver AVBP}

The LES solver AVBP developed by CERFACS and IFPEN solves the compressible Navier-Stokes equations on unstructured meshes in a conservative form. The numerical convective scheme is the TTGC scheme developed by Colin and Rudgyard [16], third order accurate in space and time while a second order Galerkin scheme is used for diffusion. In the present work, the WALE subgrid scale model proposed by Nicoud and Ducros [56] was selected to ensure a proper scaling of the turbulent viscosity at walls. To evaluate the impact of the subgrid scale model on the results, computations discussed in this paper were also done with the $\sigma$-model of Nicoud et al. [57] (not shown). No significant differences were found. Inlets and outlets are represented by the Navier-Stokes Characteristic Boundary Conditions proposed by Poinsot and Lele [60] to ensure a physical representation of acoustic waves propagation at boundaries. AVBP has been used and validated in effusion jets by Mendez and Nicoud [50] and jets in cross flow cases by Baya Toda et al. [67] and Prière et al. [61] among many other flow configurations.

\subsubsection{The thermal solver AVTP}

The conduction solver used for the solid domain is named AVTP and is developed at CERFACS. This cell-vertex/finite element code solves the heat equation on unstructured meshes. It takes into account local changes of heat capacity and conductivity with temperature. AVTP is dedicated to be coupled to LES calculations and has been used and validated in the past years notably for turbine blade and liner problems by Duchaine et al. [19,21], Florenciano [25], and Jauré et al. [34]. A second order Galerkin scheme is used for the diffusion term while time integration is done using an implicit first order forward Euler scheme. The resolution of the implicit system is performed thanks to a parallel matrix free conjugate gradient method [27].

\subsection{Coupling parameters}

The Parallel Coupling Strategy (PCS) is the same as the one used by Florienciano and Bruel [24]. This approach relies on two different solvers, each solving a medium (the flow or the plate), which exchange data at a common boundary interface. Coupling libraries, embedded within the solvers, ensure the information exchange between the two entities. The coupling of the LES and conduction solvers is achieved following the methodology of Jauré et al. [34] both in terms of data exchanged and frequency. The convective heat flux $q_{\text {conv }}$ is provided by the fluid domain to the solid one which gives back a wall temperature $T_{\text {wall }}$ to the fluid domain. To ensure the performance of the coupling, the parallel coupler OpenPALM developed by CERFACS and ONERA is used [20]. The coupling strategy has been validated and used in previous works of Duchaine et al. [21] and Berger et al. [10].

The CPU cost, for each simulation is reported in Table 5, taking the unresolved simulation as reference. The CPU cost of the coupled simulation is twice the adiabatic one due to the convergence of the solid temperature. Wall resolved simulations require two orders of magnitude more CPU time than the simulation based on the homogeneous model for the perforated plate.

Table 5

Comparison of the scaled CPU costs.

\begin{tabular}{cc}
\hline Simulation & Scaled CPU \\
\hline Resolved coupled & 192 \\
Resolved adiabatic & 97 \\
Unresolved & 1 \\
\hline
\end{tabular}




\section{Comparison between the resolved coupled and the resolved adiabatic simulations}

The resolved coupled computation is a spatially evolving LES of a multi perforated plate representative of an aero engine at realistic operating conditions. Figure 6 presents an instantaneous isocontour of the cold air mass fraction $\left(Y_{\text {coolant }}=0.7\right)$ as well as the temperature field over the mid plane (see Fig. 5). The jets present distinct behaviors depending on their position on the plate. The first rows penetrate deeper in the hot flow but do not prevent the hot gas from reaching the solid surface. In contrast, the jets located after the 5th row interact to form a protecting film. This is very similar to the film cooling visualization of Rouvreau [62].

To assess the difference between the resolved coupled and the adiabatic computations, temperature and axial mass flow rate profiles are presented on Fig. 7. 3D data are time and spatially averaged in the spanwise direction. Results are presented as a function of $Y^{*}$, the distance from the plate normalized by the inter-row distance $\Delta$ defined on Fig. $7(\Delta=11.68 d)$. Figure 7 shows such profiles at four axial positions along the multi-perforated plate, in the injection side. The first two positions correspond to the third and tenth rows. The last two positions correspond to 3 and 25 diameters downstream of the last perforation where the film is no more fed by coolant injection.

Overall, the results show a marginal effect of the thermal coupling on the flow quantities. The only significant effect on the temperature profiles lie on $Y^{*}<0.05$ where the isothermal condition induces strong temperature gradients. Assuming adiabaticity for liners is therefore acceptable when focusing on engine performances. On the contrary, adiabatic calculations underestimate the temperature drop close to the wall, which is critical when focusing on the wall temperature.

The expression of the Biot number is given in Eq. (14), where $h$, $e$ and $\lambda_{s}$ denote the heat transfer coefficient at the interface between the fluid and the solid, the thickness of the plate and the thermal conductivity of the plate.

$$
B_{i}=\frac{h e}{\lambda_{s}} .
$$

According to Florenciano and Bruel [24], the Biot number of MAVERIC-H is very small $(\approx 0.013)$. To first order, it means that the temperature variation across the wall thickness can be neglected on both sides of the multi-perforated plate ( $T_{\text {wallhot }}=T_{\text {wallcold }}=T_{\text {wall }}$ ). In addition, in all this study, the wall temperature is averaged in the spanwise direction. Thus, the wall temperature depends only on the streamwise location, $T_{\text {wall }}=T_{\text {wall }}(x)$. As shown in Fig. 8, this approximation is indeed well supported by the resolved coupled simulation. The mean difference between $T_{\text {wallhot }}$ and $T_{\text {wallcold }}$ is about $6.9 \mathrm{~K}$, which is less than $1 \%$ of the difference between $T_{\text {hot }}$ and $T_{\text {cold }}$. In contrast, the resolved adiabatic simulation leads to adiabatic temperature distributions which are significantly different between the suction and injection sides of

\section{Temperature $[\mathrm{K}]$}

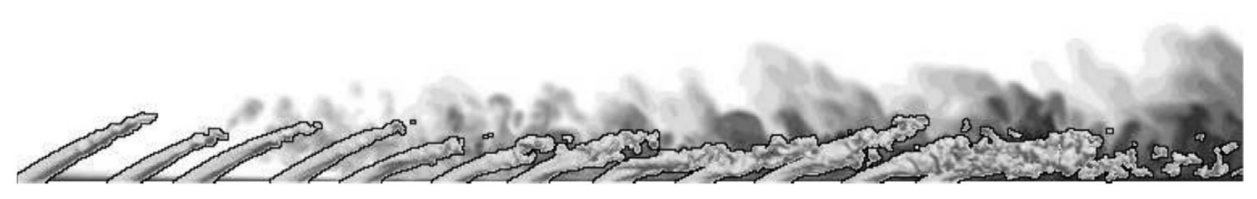

Fig. 6. Instantaneous isocontour of cold air $\left(Y_{\text {coolant }}=0.7\right)$ and temperature field at the mid plane (see Fig. 5 for localization) from the fully coupled resolved simulation.

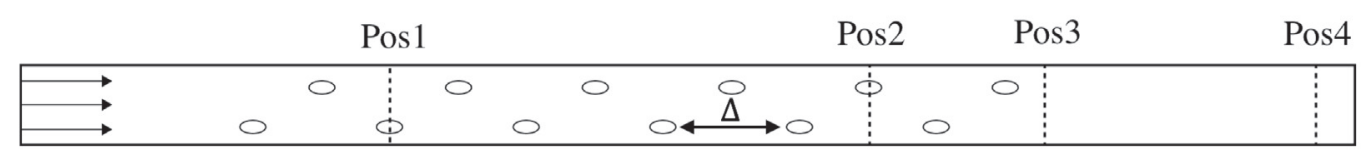

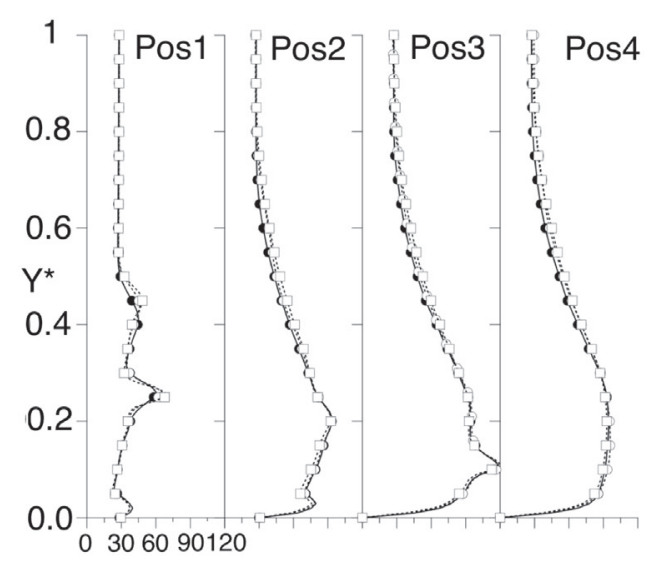

(a) Axial mass flux $\left(\mathrm{kg} \cdot \mathrm{m}^{-2} \cdot \mathrm{s}^{-1}\right)$

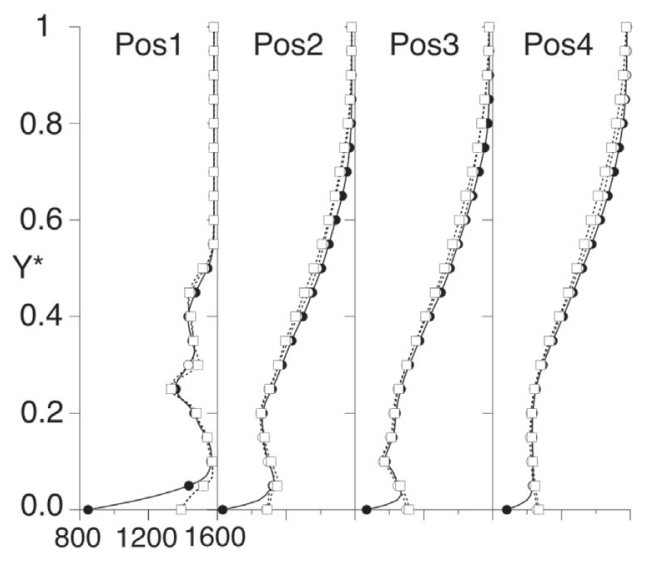

(b) Temperature (K)

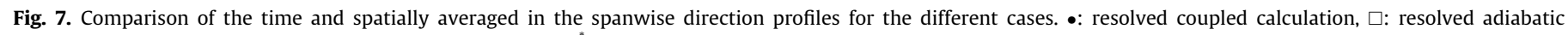
calculation. The ordinate axis is the non-dimensional height $\mathrm{Y}^{*}$, the ratio between the wall distance $\mathrm{y}$ and the inter-row distance $\Delta$. 


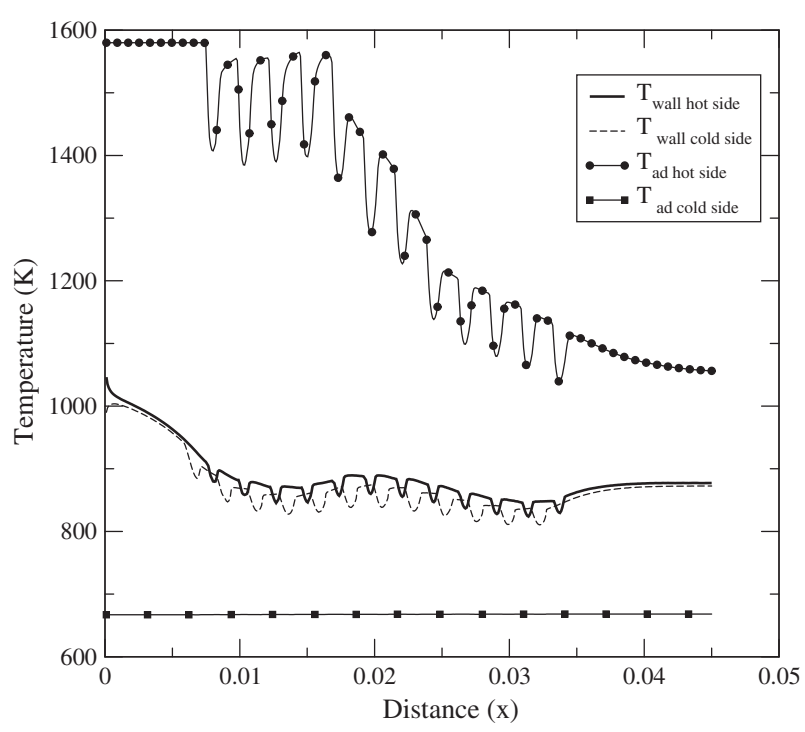

Fig. 8. Evolution of the temperature, which is time and spatially averaged in the spanwise direction for both the resolved coupled case and the resolved adiabatic case.

the plate. The adiabatic temperature on the suction side remains close to the cold temperature $T_{\text {adcold }} \approx T_{\text {cold }}$ (see Fig. 8).

\section{Global energy balance of the resolved coupled case}

A proper methodology to assess the temperature of the plate under realistic conditions must account for the main contributors in the energy balance. To identify these big players, a quantitative analysis of the heat transfers within the plate is achieved by considering the energy budget over two control volumes encompassing the fluid inside the apertures and the perforated liner solid part respectively, as shown in Figs. 9 and 10. The control volume for the solid medium starts at $\Delta x / 2$ upstream of the first row and finishes at $\Delta x / 2$ downstream of the last row of holes. The subscripts 1 and 2 refer to the injection and suction sides respectively. Denoting by $s_{1}$ and $s_{2}$ the hole outlet and inlet surfaces, $\overline{s_{1}}$ and $\overline{s_{2}}$ correspond to the liner surfaces in contact with the hot and cold crossflows respectively while $s_{u}$ and $s_{d}$ represent the upstream and downstream surfaces of the plate. The solid and fluid volumes of control can exchange heat through their common interface, which is the inner surface $s_{h}$ of each aperture. Flux exchanged by the two media are recalled in Figs. 9 and 10 where the inward normal relative to the fluid and solid domains are denoted by $\overrightarrow{n_{f}}$ and $\overrightarrow{n_{s}}$ respectively.

The diffusive flux in the fluid is noted as $\overrightarrow{q_{\text {diff }}}$, the convective flux on each side of the plate as $\overrightarrow{q_{\text {conv }}}$ (see Fig. 9). The fluid-solid flux within the aperture is noted as $\overrightarrow{q_{\text {hole }}}$ while the same flux through the liner's surface is call $\overrightarrow{q_{d i f f}^{*}}$. The conductive flux within the solid is denoted by $\overrightarrow{q_{\text {cond }}}$. They are all reported in Table 6 . The fluid velocity vector is referred as $\vec{V}$, its components will be denoted $U, V, W$ for the streamwise, normal, and spanwise directions respectively. The total energy equation integrated over the control volumes and over time yields Eqs. (15) and (16), for the fluid and solid media respectively:

$$
\begin{aligned}
& \int_{s_{1}, s_{2}} \rho E_{t} \vec{V} \cdot \overrightarrow{n_{f}} d S+\int_{s_{1}, s_{2}} P \vec{V} \cdot \overrightarrow{n_{f}} d S+\int_{s_{1}, s_{2}} \overrightarrow{q_{d i f f}} \cdot \overrightarrow{n_{f}} d S \\
&+\int_{S_{h}} \overrightarrow{q_{h o l e}} \cdot \overrightarrow{n_{f}} d S-\int_{s_{1}, s_{2}}(\overline{\bar{\tau}} \cdot \vec{V}) \cdot \overrightarrow{n_{f}} d S=0 \\
& \int_{s_{u}, S_{d}} \overrightarrow{q_{\text {cond }}} \cdot \overrightarrow{n_{s}} d S+\int_{\overline{s_{1}, s_{2}}} \overrightarrow{q_{d i f f}^{*}} \cdot \overrightarrow{n_{s}} d S+\int_{s_{h}} \overrightarrow{q_{\text {hole }}} \cdot \overrightarrow{n_{s}} d S=0
\end{aligned}
$$

The viscous tensor is defined as $\overline{\bar{\tau}}=2 \mu S-\frac{2}{3} \mu \operatorname{tr}(S) \mathbb{I}$ where $S=\frac{1}{2}\left(\nabla \vec{V}+\nabla \vec{V}^{T}\right)$ is the strain rate tensor and $\mathbb{I}$ the $3 \times 3$ identity matrix. The diffusive fluxes, $\overrightarrow{q_{\text {diff }}}$ and the conductive flux, $\overrightarrow{q_{\text {cond }}}$, are modeled thanks to the Fourier's law $(\vec{q}=-\lambda \vec{\nabla} T)$ where $\lambda$ is the thermal conductivity of the appropriate medium. Splitting Eq. (15) into three parts in order to underline the contribution of each surface yields:

$$
\begin{aligned}
& \int_{s_{2}}\left(\rho H_{t} \vec{V}-\lambda_{f} \vec{\nabla} T_{f}-\overline{\bar{\tau}} \vec{V}\right) \cdot \overrightarrow{n_{f}} d s \\
& \quad+\int_{s_{1}}\left(\rho H_{t} \vec{V}-\lambda_{f} \vec{\nabla} T_{f}-\overline{\bar{\tau}} \vec{V}\right) \cdot \overrightarrow{n_{f}} d s+\int_{s_{h}} \overrightarrow{q_{h o l e}} \cdot \overrightarrow{n_{f}} d S=0 .
\end{aligned}
$$

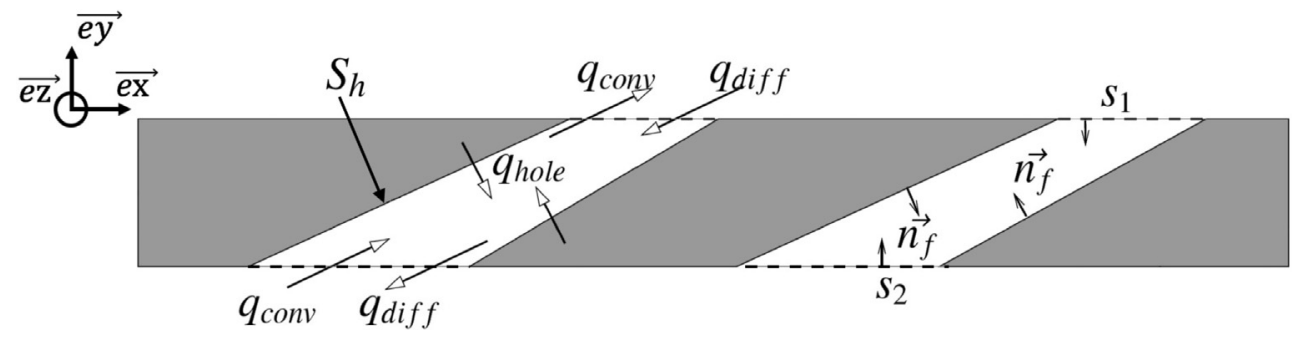

Fig. 9. Representation of the different fluxes and the inward normal of the fluid control volume.

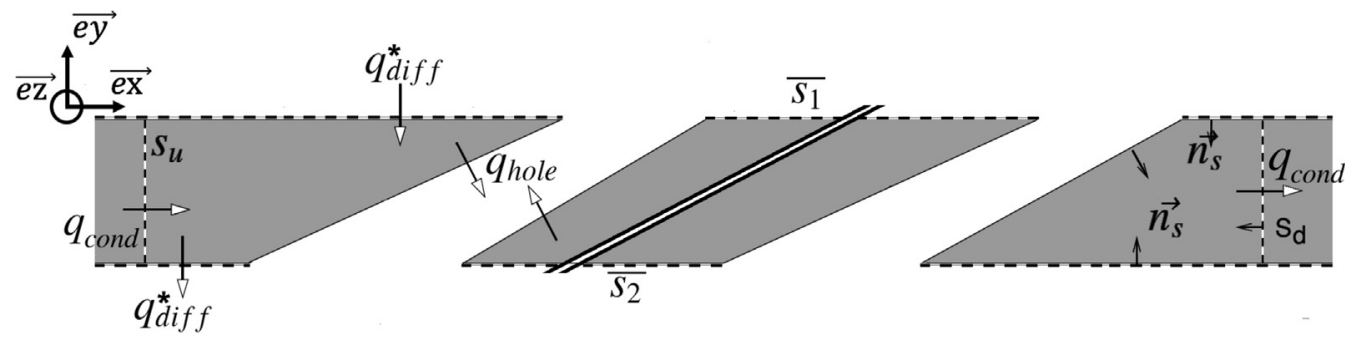

Fig. 10. Representation of the different fluxes and the inward normal of the solid control volume. 
Table 6

Definition of the fluxes involved in the thermal balances. $\rho H_{t} \vec{V}$ corresponds to the enthalpy exchange within the orifice. The diffusive fluxes at the fluid-solid interface $\left(\overrightarrow{q_{\text {diff }}^{\rightleftarrows}}\right.$ and $\left.\overrightarrow{q_{\text {hole }}}\right)$ are modeled thanks to a heat transfer coefficient $\mathrm{h}$ and a reference temperature $T_{\text {ref }}$, see Section 6.

\begin{tabular}{cccc}
\hline Flux & Applicable surface & Expression & Modeling expression \\
\hline $\overrightarrow{q_{\text {conv }}}$ & $s_{1}, s_{2}$ & $\rho H_{t} \vec{V}=\rho E_{t} \vec{V}+P \vec{V}$ & N/A \\
$\overrightarrow{q_{\text {diff }}}$ & $s_{1}, s_{2}$ & $-\lambda_{f} \vec{\nabla} T_{f}$ & N/A \\
$\overrightarrow{q_{\text {diff }}^{*}}$ & $\overline{s_{1}}, \overline{s_{2}}$ & $-\lambda_{s} \vec{\nabla} T_{s}=-\lambda_{f} \vec{\nabla} T_{f}$ & $h\left(T-T_{\text {ref }}\right)$ \\
$\overrightarrow{q_{\text {hole }}}$ & $s_{h}$ & $-\lambda_{s} \vec{\nabla} T_{s}=-\lambda_{f} \vec{\nabla} T_{f}$ & $h\left(T-T_{\text {ref }}\right)$ \\
$\overrightarrow{q_{\text {cond }}}$ & $s_{u}, s_{d}$ & $-\lambda_{s} \vec{\nabla} T_{s}$ & N/A \\
\hline
\end{tabular}

Since $\overrightarrow{n_{f}}=\overrightarrow{e_{y}}$ on $S_{2}$ and $\overrightarrow{n_{f}}=-\overrightarrow{e_{y}}$ on $s_{1}$, Eq. (17) leads to:

$$
\begin{aligned}
& \int_{s_{2}}\left(\rho H_{t} V-\lambda_{f} \frac{\partial T_{f}}{\partial y}-(\overline{\bar{\tau}} \cdot \vec{V})_{y}\right) d s \\
& \quad-\int_{s_{1}}\left(\rho H_{t} V-\lambda_{f} \frac{\partial T_{f}}{\partial y}-(\overline{\bar{\tau}} \cdot \vec{V})_{y}\right) d s+\int_{s_{h}} \overrightarrow{q_{\text {hole }}} \cdot \overrightarrow{n_{f}} d S=0,
\end{aligned}
$$

where $(\overline{\bar{\tau}} \cdot \vec{V})_{y}=\tau_{x y} U+\tau_{y y} V+\tau_{z y} W$ is the normal component of $(\overline{\bar{\tau}} \cdot \vec{V})$.

Note that the viscous contributions in the integral over $s_{1}$ and $s_{2}$, $\lambda_{f} \frac{\partial T_{f}}{\partial y}$ and $(\overline{\bar{\tau}} \cdot \vec{V})_{y}$, can be neglected in front of the inviscid contribution $\rho H_{t} V$ (they represent less than $0.1 \%$, not shown). Thus, Eq. (18) becomes:

$$
\int_{s_{2}} \rho H_{t} V d s-\int_{s_{1}} \rho H_{t} V d s+\int_{s_{h}} \overrightarrow{q_{h o l e}} \cdot \overrightarrow{n_{f}} d S=0 .
$$

Table 7 displays the values of the three terms in Eq. (19) and shows that the energy budget over the aperture is reasonably well balanced. The absolute error is $0.8 \mathrm{~W}$ corresponding to $0.3 \%$ of the energy flux penetrating the hot flow ( $10 \%$ when compared to the thermal power exchanged within the aperture). The figures in Table 7 also show that the fluid flowing through the apertures is slightly heated by the plate, the gain (the $s_{h}$ integral term) being $\approx 4 \%$ of the total heat flux flowing through the plate. This contributes to the cooling of the plate, on top of the shielding effect often put forward.

The energy budget for the solid medium is also well balanced, as illustrated by the values of the contributions to Eq. (16) reported in Table 8. To first order the heat extracted within the apertures ( $\overline{s_{h}}$ integral term) is compensated by the difference between the diffusive fluxes on both plate faces, as it would be the case for an infinitely long plate without side effect. The flux transferred to the fluid within the perforations $\left(\int_{s_{h}} \overrightarrow{q_{\text {hole }}} \cdot \overrightarrow{n_{f}} d s\right)$ represents about $44 \%$ of the flux entering the plate at the injection side $\left(\int_{\overline{s_{1}}} \overrightarrow{q_{d i f f}^{*}} \cdot \overrightarrow{n_{s}}\right)$. This is in good agreement with Cottin's conclusion [17]. The longitudinal diffusion $\overrightarrow{q_{\text {cond }}}$ is smaller than the normal

\section{Table 7}

Time averaged wall energy fluxes. Expression and values of the fluxes (in W) relevant to the fluid domain.

\begin{tabular}{cccc}
\hline Expression & $\int_{s_{2}} \rho H_{t} V d s$ & $\int_{s_{1}} \rho H_{t} V d s$ & $\int_{s_{h}} \overrightarrow{q_{h o l e}} \cdot \overrightarrow{n_{f}} d s$ \\
Contribution (W) & 221.0 & 230.0 & 8.2 \\
\hline
\end{tabular}

diffusion $\overrightarrow{q_{\text {diff }}^{*}}$ although not negligible at the ends of the plate and locally near the holes (not shown here). The perforated portion of the plate is the coldest part of the plate, explaining why the conductive heat flux at both ends of the plate $q_{\text {cond }}$ is positive (contributions of $s_{d}$ and $s_{u}$ in Table 8).

For the operating point considered, the convective fluxes play a significant role. At the injection side, from the fluid point of view, the solid only contributes to $8.1 \%$ of the fluid energy flux ( $\int_{\bar{s}_{1}} \vec{q}_{\text {diff }} \cdot \overrightarrow{n_{s}} d s$ in Table 8 compared to $\int_{s_{1}} \rho H_{t} V d s$ in Table 7). Similar conclusions were drawn by Mendez and Nicoud [49] regarding the weak contribution of the viscous flux on the dynamics around the plate. For this range of operating point, a first order thermal model for effusion should focus on the inviscid part of the heat flux. The fact that the heat transfer through the solid represent less than $10 \%$ of the total energy exchanged between the cold and hot streams also justifies why the resolved adiabatic and coupled simulations lead to very similar results (see Section 4).

\section{Low order modeling of the temperature of the plate}

As showed in Sections 4 and 5, the heat transfer through the solid is moderate compared to the convective flux through the apertures. Thus, an adiabatic computation provides a fair description of the flow field relevant to the coupled case. This shows that it might be possible to build a reasonable assessment of the wall temperature by analyzing the outcome of an adiabatic computation. At steady state, the sum of the heat fluxes entering the multi-perforated plate should balance. From Table 8, the three main contributors to the heat budget are the diffusive heat fluxes over the cold and the hot side of the plate and within the apertures. Thus, the following global relation for the plate should hold to first order without diffusion heat fluxes at extremities:

$$
-\int_{\overline{s_{1}}} \overrightarrow{q_{d i f f}^{*}} \cdot \overrightarrow{n_{s}} d s \approx \int_{\overline{s_{2}}} \overrightarrow{q_{d i f f}^{*}} \cdot \overrightarrow{n_{s}} d s+\int_{s_{h}} \overrightarrow{q_{\text {hole }}} \cdot \overrightarrow{n_{s}} d s
$$

Introducing the heat transfer coefficients $h_{\text {hot }}, h_{\text {cold }}$ and $h_{\text {hole }}$ to model these fluxes and considering that $T_{\text {refhot }}=T_{\text {adhot }} ; T_{\text {refcold }}=T_{\text {cold }}$ and $T_{\text {refhole }}=T_{\text {cold }}$ leads to:

$$
h_{\text {hot }}\left(\overline{T_{\text {wall }}}-\overline{T_{\text {adhot }}}\right) \overline{S_{1}} \approx\left(\overline{T_{\text {cold }}}-\overline{T_{\text {wall }}}\right)\left(h_{\text {cold }} \overline{S_{2}}+h_{\text {hole }} S_{h}\right),
$$

where $\overline{T_{\text {wall }}}$ corresponds to the space averaged value of the wall temperature. The assumption $T_{\text {refhole }}=T_{\text {cold }}$ is justified by the fact that the boundary layer on the suction side is continuously sucked along the plate. Thus the solid is always exposed to $T_{\text {cold }}$ on this side. This is well supported by the results of Fig. 8 .

A simple model for assessing the temperature of the plate $\left(\overline{T_{\text {wall }}^{\text {model }}}\right)$ could thus have the form:

$$
\overline{T_{\text {wall }}^{\text {model }}}=\frac{\overline{T_{\text {cold }}}+R \overline{T_{\text {adhot }}}}{1+R}, \quad \text { with } \quad R=\frac{h_{\text {hot }} \overline{s_{1}}}{h_{\text {cold }} \overline{s_{2}}+h_{\text {hole }} s_{h}} .
$$

Using Eq. (22) to assess the wall temperature requires the knowledge of $R$ and $\overline{T_{\text {adhot }}}$. $R$ can be recovered from correlations and from geometrical parameters as a function of the porosity.

\begin{tabular}{|c|c|c|c|c|c|}
\hline Expression & $\int_{s_{h}} \overrightarrow{q_{\text {hole }}} \cdot \overrightarrow{n_{s}} d s$ & $\int_{\overline{s_{1}}} \overrightarrow{q_{d i f f}^{*}} \cdot \overrightarrow{n_{s}} d s$ & $\int_{\overline{s_{2}}} \overrightarrow{q_{d i f f}^{*}} \cdot \overrightarrow{n_{s}} d s$ & $\int_{s_{u}} \overrightarrow{q_{\text {cond }}} \cdot \overrightarrow{n_{s}} d s$ & $\int_{s_{d}} \overrightarrow{q_{\text {cond }}} \cdot \overrightarrow{n_{s}} d s$ \\
\hline Value (W) & -8.2 & 18.6 & -11.7 & 0.9 & 0.4 \\
\hline
\end{tabular}
The following values for the heat transfer coefficients can be determined from Cottin [17] and Florenciano and Bruel [24]: $h_{\text {hot }}=498$ $\mathrm{W} \mathrm{m}^{-1} \mathrm{~K}^{-1}, h_{\text {cold }}=582 \mathrm{~W} \mathrm{~m}^{-1} \mathrm{~K}^{-1}, h_{\text {hole }}=1680 \mathrm{~W} \mathrm{~m}^{-1} \mathrm{~K}^{-1}$. Then,

Table 8

Flux contributions to the energy budget of heat equation in the solid medium. The first term is the opposite of the last column in Table 7 . 
introducing the area of the geometrical surfaces of interest $\left(\overline{s_{1}}=5.99 \cdot 10^{-6} \mathrm{~m}^{2}, \overline{s_{2}}=5.74 \cdot 10^{-6} \mathrm{~m}^{2}, s_{h}=2.51 \cdot 10^{-6} \mathrm{~m}^{2}\right)$, one obtains a global value of $R \approx 0.4$.

The previous expression (Eq. (22)) gives the global mean temperature (spatially averaged) of the wall but for more complex configurations where the heterogeneity of plate temperature is important for design, a local model for $T_{\text {wall }}$ is mandatory. To do so, and considering an homogeneous solid medium, Eq. (20) can be written at a given axial position. Then, using a 1D approximation in the context of an homogeneous multiperforated plate, leads to:

$$
T_{\text {wall }}(x)=\frac{T_{\text {cold }}+R(x) T_{\text {refhot }}(x)}{1+R(x)}
$$

Considering that $T_{\text {refhot }}(x)=T_{\text {adhot }}(x)$, the adiabatic temperature from the adiabatic resolved computation, $R(x)$ can be approximated as follow:

$$
R(x)=\frac{T_{\text {wall }}(x)-T_{\text {cold }}}{T_{\text {adhot }}(x)-T_{\text {wall }}(x)} .
$$

Figure 11 compares the evolution of $R(x)$ along $x$ evaluated at discrete positions (between two row of holes), with the global value of $R$.

The mean value of $R(x)$ is 0.36 which is close to $R$. Also this figure shows that whatever the position theses ratios are close, so $R(x)$ can be approximated by the global ratio, and thus Eq. (23) becomes:

$$
T_{\text {wall }}(x) \approx \frac{T_{\text {cold }}+R T_{\text {refhot }}(x)}{1+R},
$$

The key point to determine $T_{\text {wall }}$ is thus to define a reference temperature on the hot side of the plate. The reference temperature on the hot side of the plate $\left(T_{\text {refhot }}\right)$ results from the turbulent mixing between the hot cross flow $\left(T_{\text {hot }}\right)$ and the injected cold gas $\left(T_{\text {cold }}\right)$. Cottin [17] suggested to take the temperature at the first computational node above the wall $\left(T_{F N}\right)$ as a surrogate of $T_{\text {refhot }}$. This surrogate leads to wrong result when available computations are unresolved and thus multi-perforated plate are modeled. Other possibilities to estimate $T_{\text {refhot }}$ have to be considered. A crude guess could be $T_{\text {refhot }} \approx T_{\text {hot }}$, neglecting the near wall temperature decrease due to the cold gas injection. In this paper, a more robust estimator of $T_{\text {refhot }}$ (denoted $T_{\text {mix }}$ ) is proposed based on a local average over a

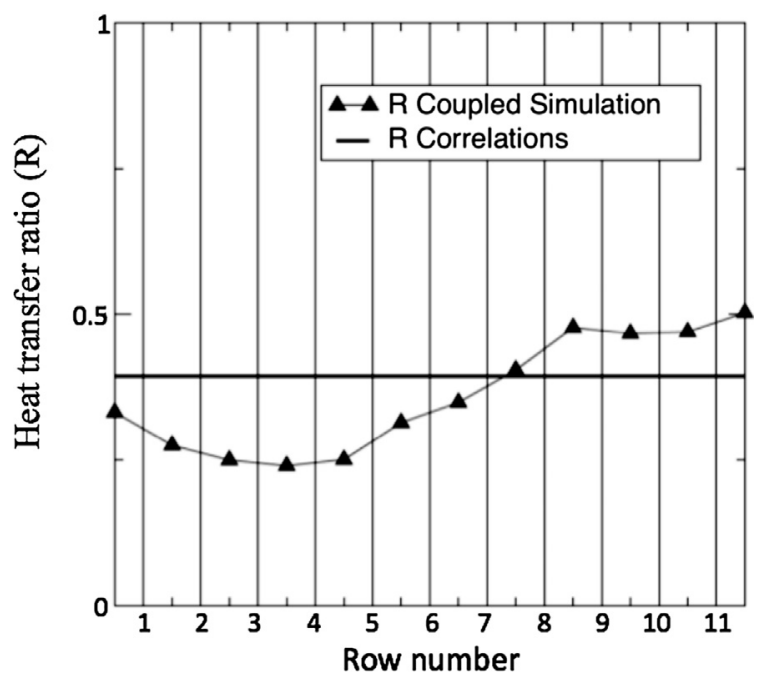

Fig. 11. Ratio of heat transfer coefficients appearing in Eqs. (22) and (24) estimated at each inter-row from the resolved coupled computation $(\mathbf{\Lambda})$ and from the correlations of Cottin [17] (-) recalled in Eqs. (7)-(11). relevant distance $\delta$ in the normal direction to the perforated liner. Regarding the averaging procedure, three options were tested: spatial averaging (Eq. (26)), velocity averaging (Eq. (27)) and momentum averaging (Eq. (28)).

$$
\begin{gathered}
T_{\text {mix }}^{S}(\delta)=\frac{\int_{\delta} \bar{T}(y) d y}{\delta}, \\
T_{\text {mix }}^{V}(\delta)=\frac{\int_{\delta} \bar{U}(y) \bar{T}(y) d y}{\int_{\delta} \bar{U}(y) d y}, \\
T_{\text {mix }}^{M}(\delta)=\frac{\int_{\delta} \bar{\rho}(y) \bar{U}(y) \bar{T}(y) d y}{\int_{\delta} \bar{\rho}(y) \bar{U}(y) d y} .
\end{gathered}
$$

The corresponding non dimensional mixing temperatures, $\theta_{\text {mix }}$, may be defined as follows:

$$
\theta_{\text {mix }}=\frac{T_{\text {mix }}-T_{\text {cold }}}{T_{\text {hot }}-T_{\text {cold }}} .
$$

By post-processing either the unresolved or the resolved adiabatic computations, profiles of the evolution of the non-dimensional mixing temperature with respect to the integration depth $\delta$ are shown in Fig. 12 at the 9-10 inter-row position. The thermal boundary layer thickness, $\delta_{t h}$, is taken as $99 \%$ of the non dimensional temperature. In the resolved case it is about $43 \%$ of the channel height and leads to $Y^{*}=0.9$ (horizontal line in Fig. 12(a)). In the unresolved case, it corresponds to $Y^{*}=0.8$. Note that a variation of $10 \%$ on the integration length leads to a variation of $4 \%$ and $6 \%$ on resolved and unresolved case, respectively. In view of these results, and to simplify the model as much as possible, the integration length will be imposed to $Y^{*}=0.9$ for both resolved and unresolved case in all this section.

On Fig. 13, results from the two simple reference temperature estimators $\left(\theta_{\text {hot }}\right.$ and $\left.\theta_{F N}\right)$ and the three present estimators of the reference temperature $\left(\theta_{\text {mix }}^{M}, \theta_{\text {mix }}^{V}, \theta_{\text {mix }}^{S}\right)$ are compared for the two adiabatic cases. The results are scaled as follows: $\Theta_{\text {mix }}=\theta_{\text {mix }} / \theta_{\text {adhot }}$, where $\theta_{\text {adhot }}$ corresponds to $\theta_{\mathrm{FN}}$ from the resolved adiabatic simulation. At the beginning of the plate, all reference temperature estimators predict the same adiabatic plate temperature because $\theta_{\text {refhot }}=\theta_{\text {hot }}$. However, reference temperature estimators are needed for unresolved simulations where the plate is modeled as a homogeneous boundary condition. In this case, $\theta_{F N}$ does a poor job collapsing with the $\theta_{\text {cold }}$ value. The momentum weighting $\theta_{\text {mix }}^{M}$ gives the best values and trend for both cases. From now $T_{\text {mix }}$ will denote $T_{\text {mix }}^{M}\left(\delta_{t h}\right)$ which has been proved to be the best estimator of the reference temperature.

Once $R$ and $T_{\text {refhot }}$ have been assessed, Eq. (25) can be used to compute $T_{\text {wall }}^{\text {model }}$, an estimator of the plate temperature. For a more practical comparison, a non dimensional estimation is computed as follows:

$$
\theta_{\text {wall }}^{\text {model }}=\frac{T_{\text {wall }}^{\text {model }}-T_{\text {cold }}}{T_{\text {hot }}-T_{\text {cold }}} .
$$

Different combinations have been tested as reported in Table 9. The performances of the different reference temperature estimators are displayed in Fig. 14 where they are compared to $\theta_{\text {wall }}$, the wall temperature computed from the resolved coupled simulation. $\theta_{\text {wall }}^{\text {model } 1}$ to $\theta_{\text {wall }}^{\text {model }}$ use $R(x)$, the heat transfer coefficient ratio calculated from the coupled computation which is variable in space and are thus expected to be more accurate. However, since the goal of the present study is to propose a low cost method for the industrial modeling routine, reference temperature estimators $\theta_{\text {wall }}^{\text {model }}$ to $\theta_{\text {wall }}^{\text {model } 10}$, based on correlations for $R$ with a global value are tested. 


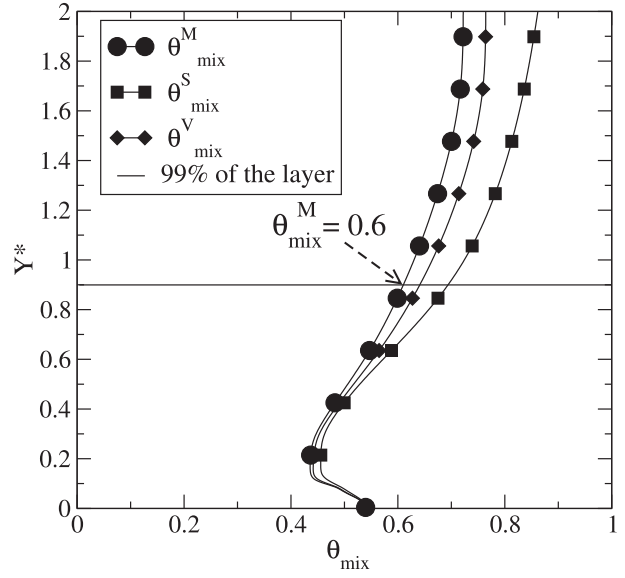

(a) Adiabatic Resolved Simulation

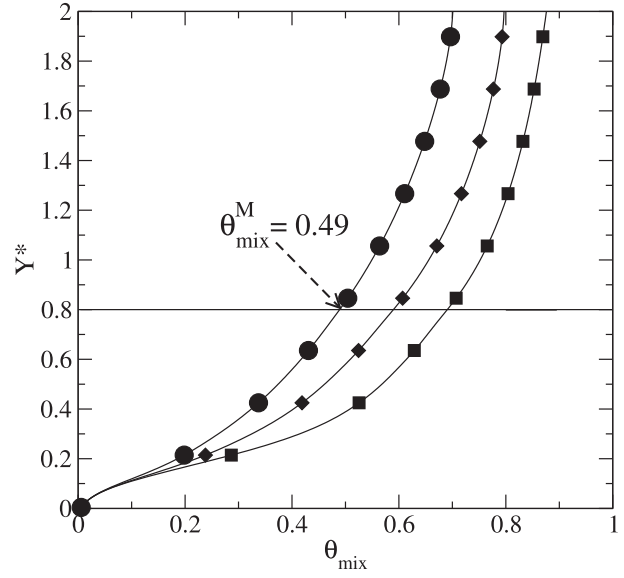

(b) Unresolved simulation

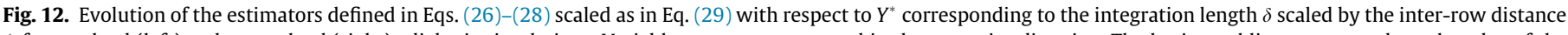

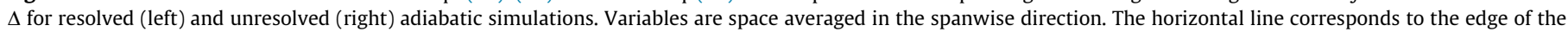
thermal boundary layer.

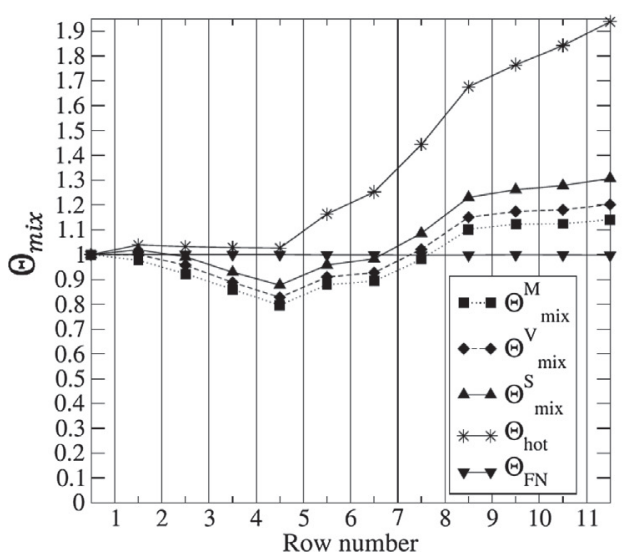

(a) Adiabatic Resolved Simulation

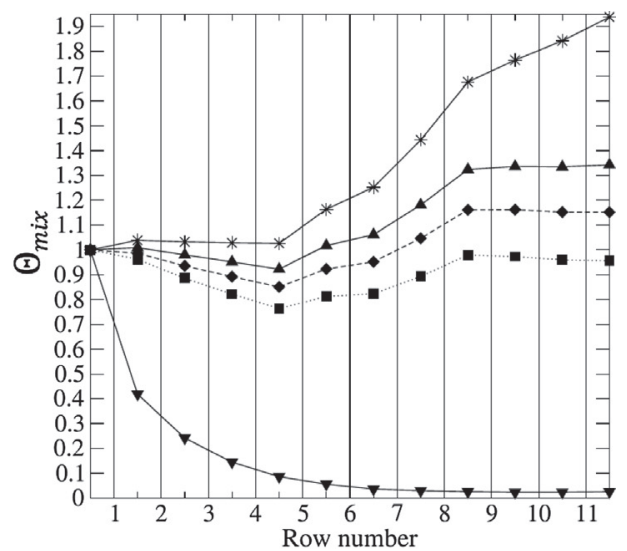

(b) Unresolved simulation

Fig. 13. Comparison of different reference temperature estimators of $\Theta_{\text {adhot }}$ applied on the resolved (left) and the unresolved (right) adiabatic simulations.

Table 9

Tested combinations.

\begin{tabular}{cccc}
\hline Name & Run type & $T_{\text {refhot }}$ from & $R$ from \\
\hline$\theta_{\text {wall }}$ & Coupled resolved & $/$ & $R(x)$ local from \\
\hline$\theta_{\text {wall }}^{\text {model }}$ & Uncoupled resolved & $T_{F N}$ & coupled simulation \\
$\theta_{\text {wall }}^{\text {model }}$ & Uncoupled resolved & $T_{\text {mix }}$ & \\
$\theta_{\text {wall }}^{\text {mode }}$ & Unresolved & $T_{F N}$ & \\
$\theta_{\text {wall }}^{\text {model }}$ & Unresolved & $T_{\text {mix }}$ & \\
$\theta_{\text {wall }}^{\text {model5 }}$ & No computation & $T_{\text {hot }}$ & \\
\hline$\theta_{\text {wall }}^{\text {model6 }}$ & Uncoupled resolved & $T_{F N}$ & $R$ global from correlations \\
$\theta_{\text {wall }}^{\text {model }}$ & Uncoupled resolved & $T_{\text {mix }}$ & \\
$\theta_{\text {wall }}^{\text {model }}$ & Unresolved & $T_{F N}$ & \\
$\theta_{\text {wall }}^{\text {model }}$ & Unresolved & $T_{\text {mix }}$ & \\
$\theta_{\text {wall }}^{\text {model }}$ & No computation & $T_{\text {hot }}$ & \\
\hline
\end{tabular}

$\theta_{\text {wall }}^{\text {modi }}$ computed with $T_{F N}$ as a reference temperature on the resolved mesh and $R(x)$ from the coupled simulation gives by construction the reference wall temperature. Note that the same reference temperature estimator on the unresolved case, which requires the use of the homogeneous model [49], is far off the mark (see $\theta_{\text {wall }}^{\text {model }}$ and $\theta_{\text {wall }}^{\text {model }}$ ). When $T_{\text {hot }}$ is used to model $T_{\text {refhot }}$, the estimated wall temperature $\left(\theta_{\text {wall }}^{\text {model }}\right)$ is correct in the 5 first rows but difference with the reference value $\left(\theta_{\text {wall }}\right)$ increases downstream, once the film is established. Moreover, this reference temperature estimator combined with correlations $\left(\theta_{\text {wall }}^{\text {model } 10}\right)$ leads to an unacceptable overestimation of the wall temperature. The estimated wall temperature obtained when $T_{\text {mix }}$ is used as a model for $T_{\text {refhot }}$ is in fair agreement with the reference wall temperature. $\theta_{\text {wall }}^{\text {model }}$, $\theta_{\text {wall }}^{\text {model }}, \theta_{\text {wall }}^{\text {model }}, \theta_{\text {wall }}^{\text {model }}$ show that the present reference temperature estimator, $T_{m i x}$, is quite robust and can handle either resolved computations where holes are present or unresolved computations based on the homogeneous model of Mendez and Nicoud [49]. Among these reference temperature estimators, the most attractive one for CPU cost reasons is $\theta_{\text {wall }}^{\text {model }}$ which comes from an unresolved computation combined with correlations and produces a small error on the estimated wall temperature.

Since the proposed reference temperature estimator can be used on various effusion plates, it has been validated on another academical test case which has both different geometrical parameters and operating point. This is discussed in the following section. 


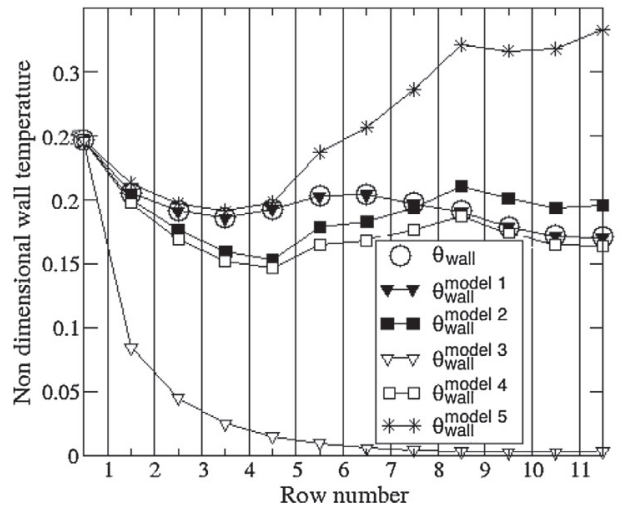

(a) R from coupled simulation

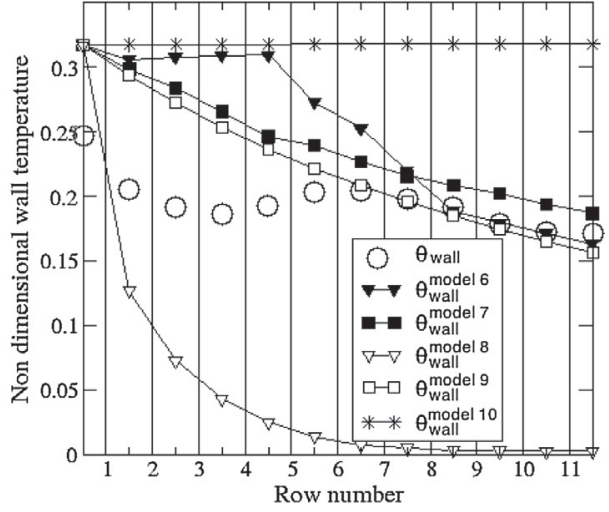

(b) $\mathrm{R}$ from Correlation

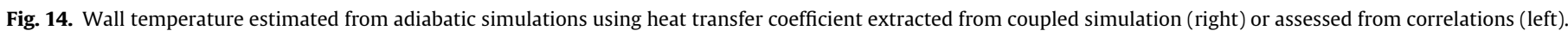

\section{Validation of the reference temperature estimator}

The reference temperature estimator is now applied to the KIAI (Knowledge for Ignition, Acoustics and Instabilities) setup developed during a EU funded Research Project. This configuration has been studied and detailed in $[47,2,3,9]$. For the present study, the blowing and density ratios are $M=3$ and $D_{R}=1$ respectively. The geometry denoted G2 in $[47,2,3,9]$ has been retained. It consists in a multi-perforated plate similar to the one considered in Section 6 . The main geometrical characteristics are given in the Table 10. The mesh considered is composed of about one million of elements. The ratio between the hole diameter and the mesh size, as introduced in Bizzari et al. [11], is equal to one; this corresponds to the typical mesh size found in numerical simulation of real combustors.

Table 10

Characteristics of the plate of interest.

\begin{tabular}{ccccccc}
\hline Diameter $(d)$ & Number of rows & $L / d$ & $\alpha$ & $\Delta x$ & $\Delta z$ & $\sigma(\%)$ \\
\hline $1.50 \mathrm{~mm}$ & 18 & 6.25 & $30^{\circ}$ & 9.15 & 7.37 & 2.32 \\
\hline
\end{tabular}

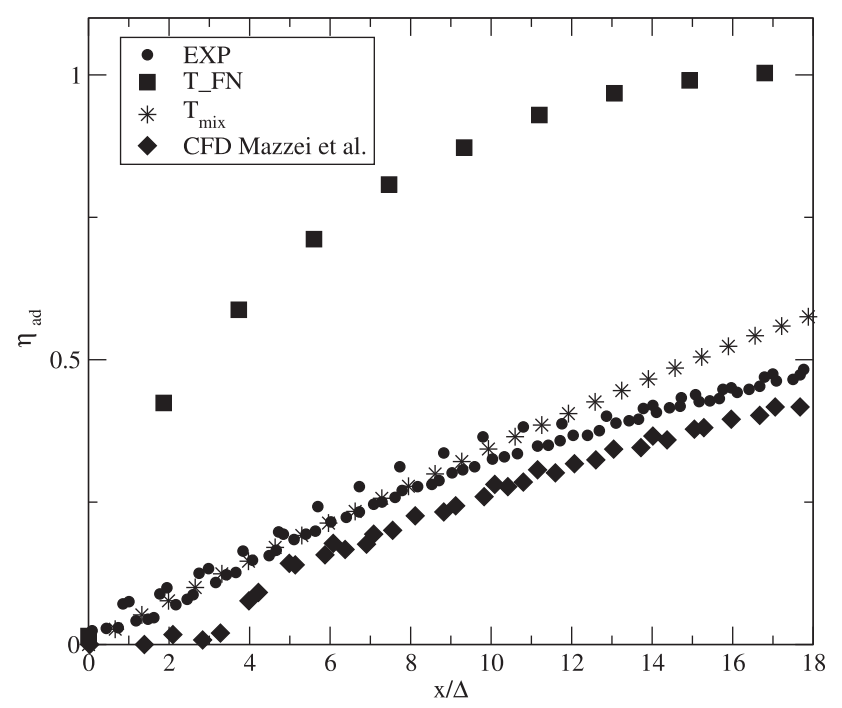

Fig. 15. Adiabatic efficiency for one of the configuration described in [47]. Experimental and hole resolved CFD results are extracted from Mazzei et al. [47]. $T_{F N}$ and $T_{m i x}$ correspond to the results obtained using either the first node value or the mixing temperature to estimate the adiabatic temperature, respectively.
A turbulent profile was imposed at the inlet, although no turbulence fluctuations were added. The multi-perforated plate was modeled using the homogeneous model [49] (note that the porosity is calculated considering the effusion angle which leads to a value of $\sigma=2.32 \%$ ). The adiabatic efficiency is presented on Fig. 15. The experimental values are presented together with the numerical data of Mazzei et al. [47] as well as the present results obtained for different estimators of the adiabatic temperature. For the adiabatic estimator of the temperature, the integration length was taken as $99 \%$ of the thermal thickness on each position, and has been extracted from the simulation. The same conclusion as in Section 6 can be drawn. The temperature directly extracted using the first node method fails to assess the proper adiabatic efficiency. On the contrary the reference temperature from the mixing temperature predicts the correct trends even if the adiabatic efficiency is overpredicted when the film cooling is not established.

\section{Application of the low-order model to a helicopter combustor}

In this section, a turboshaft reverse flow combustion chamber, as in [10], is considered (see Fig. 16). A reactive simulation with adiabatic walls, in which effusion cooling is accounted for thanks to the homogeneous model [49], has been performed with the LES solver AVBP. Such adiabatic simulation using modeled multiperforated plate is the standard in industry for predicting the combustor exit temperature profile or pollutant emissions. The objective of this section is to evaluate the low-order method, described in Section 6, for extracting the combustor liner temperature field from this computation. The $\theta_{\text {wall }}^{\text {mode }}$ estimator (see Table 9) was selected for this purpose.

The periodicity of the configuration allows to consider only one sector of the combustion chamber, comprising one injector and several primary and dilution holes. The computation was performed on a 40 million elements mesh, with the grid size being of the order of the perforation diameter near the walls. The filtered Navier-Stokes equations were integrated thanks to an explicit LaxWendroff [39] numerical scheme, second order accurate in time and space. Combustion was described by the Thickened Flame Model [15] combined with the 2-step BFER kinetic scheme [26]. The Smagorinsky [66] model was also used to account for the subgrid-scale turbulence viscosity.

The combustor simulation was averaged in time to obtain mean velocity and temperature fields within the flame tube and in the combustor casing (see Fig. 17). On the one hand, these fields were post-processed to compute locally the heat-transfer coefficients using the correlations from Cottin [17] on the cold side, within 


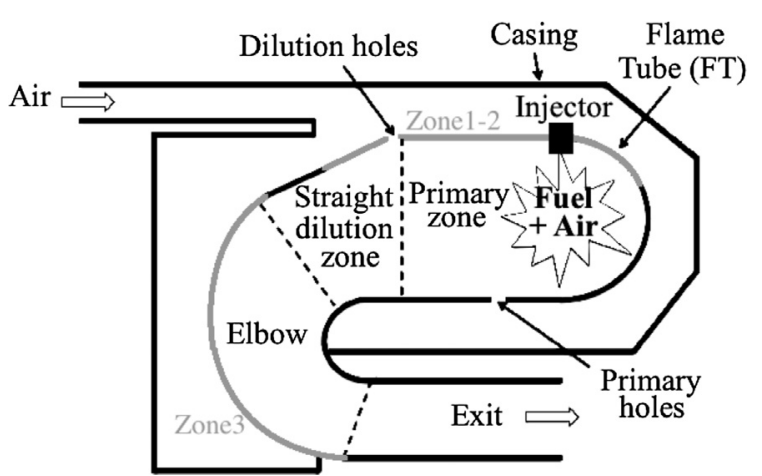

Fig. 16. Schematic view of the combustor. Zones 1,2 and 3 are used in Fig. 19 for comparison purposes. Zones 1 and 2 correspond to the external envelope of the flame tube at two azimuthal positions. Zone 3 corresponds to the external elbow.

the holes and the one from Florenciano and Bruel [24] on the hot side. This led to a global value of the $R$ coefficient, still local to each multiperforated patch since each patch is modeled by a homogeneous boundary condition. On the other hand, temperature and velocity fields were post-processed to estimate the corresponding adiabatic exchange temperature $T_{m i x}$ thanks to Eq. (28). The proposed modeling method has been recalled in Fig. 18.

The steady-state wall temperature field was then obtained thanks to Eq. (25). It should be noticed that transverse conduction within the liner is neglected in this approach, consistently with the findings of Berger et al. [10]. Figure 19 presents comparisons between the low-order temperature assessment and experimental data from thermo-color tests. Such tests are based on the use of thermo-sensitive paints, which color evolves depending on the wall temperature. The $\theta_{\text {wall }}^{\text {mode }}$ estimator leads to a fair prediction of the wall temperature levels. It also allows to localize the main hot and cold spots even if on both Zones 1 and 2, the hot part is not as wide as in experiments. Indeed, in Zone 1, the B color spot on the left is well identified, like the very hot zone on the top of the picture. In Zone 2, the D temperature zone is also well retrieved. Finally, the homogeneous temperature field of Zone 3 is nicely reproduced.

The thermo-color technique gives access to the whole combustor liner temperature field topology but is characterized by a large range of uncertainties compared to thermocouples. Indeed, one color corresponds to a range of temperature and not to a given value. That is why more-detailed comparisons should take such uncertainties into account and focus on specific temperature profiles. Figure 21 shows a comparison between numerical and experimental data as a function of the axial position $(x)$ for two lines defined in Fig. 20. The agreement is quantitatively very good on both lines when considering error bars from the tests. The temperature levels are correctly predicted from the outer-elbow (OE) to the combustor dome (Do).

The proposed low-order model based on the $\theta_{\text {wall }}^{\text {model }}$ reference temperature estimator is thus a promising approach to extract combustor wall temperature fields from unresolved adiabatic computations. Such estimations are useful in the first design iterations

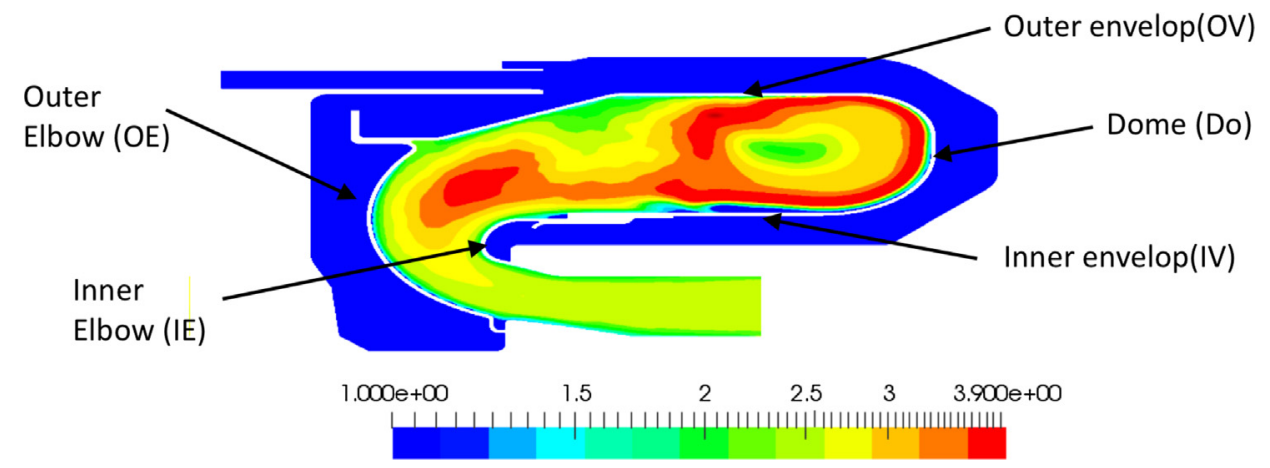

Fig. 17. Non-dimensional mean fluid temperature field. Results from an adiabatic unresolved simulation using the homogeneous model.

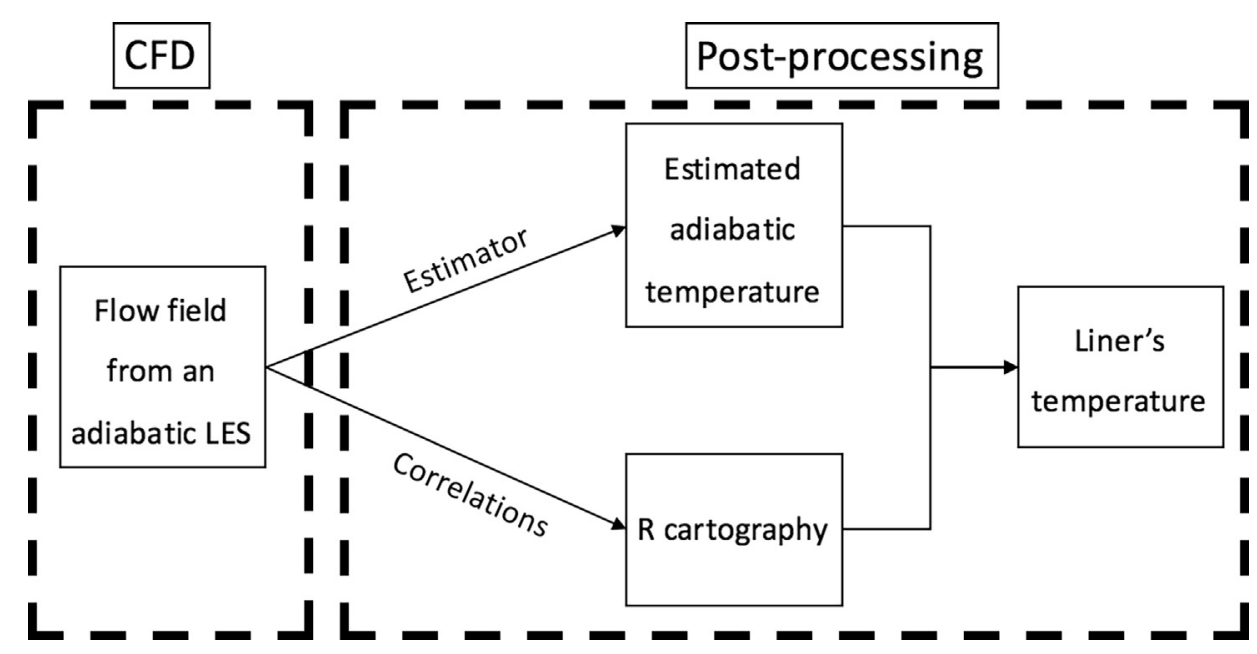

Fig. 18. Block diagram of the whole proposed computational strategy. 

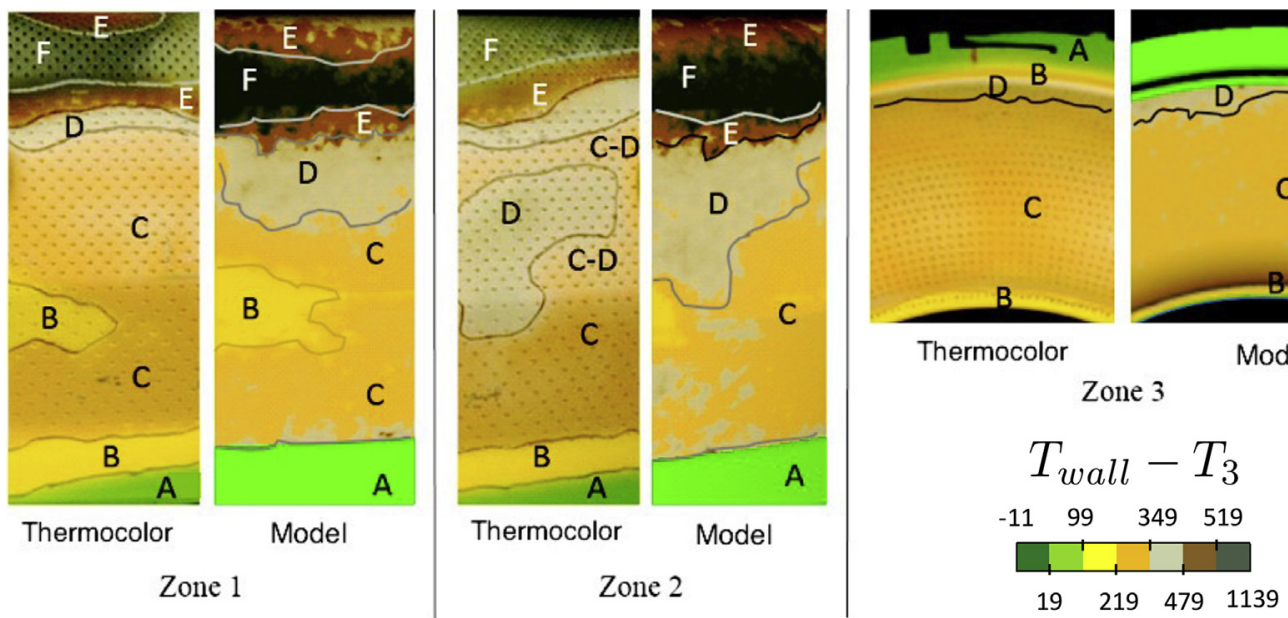

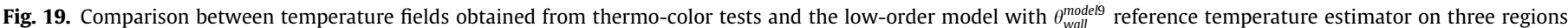

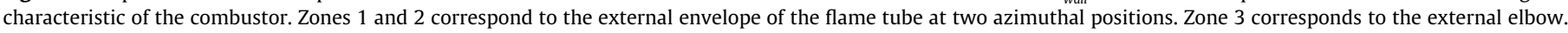
See Fig. 16 for the location of zones 1-3.

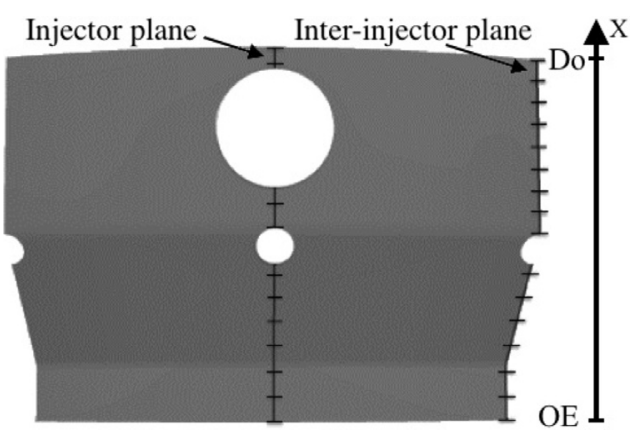

Fig. 20. Definition of the injector plane and inter-injector plane lines on a 2D map extract from Fig. 17.
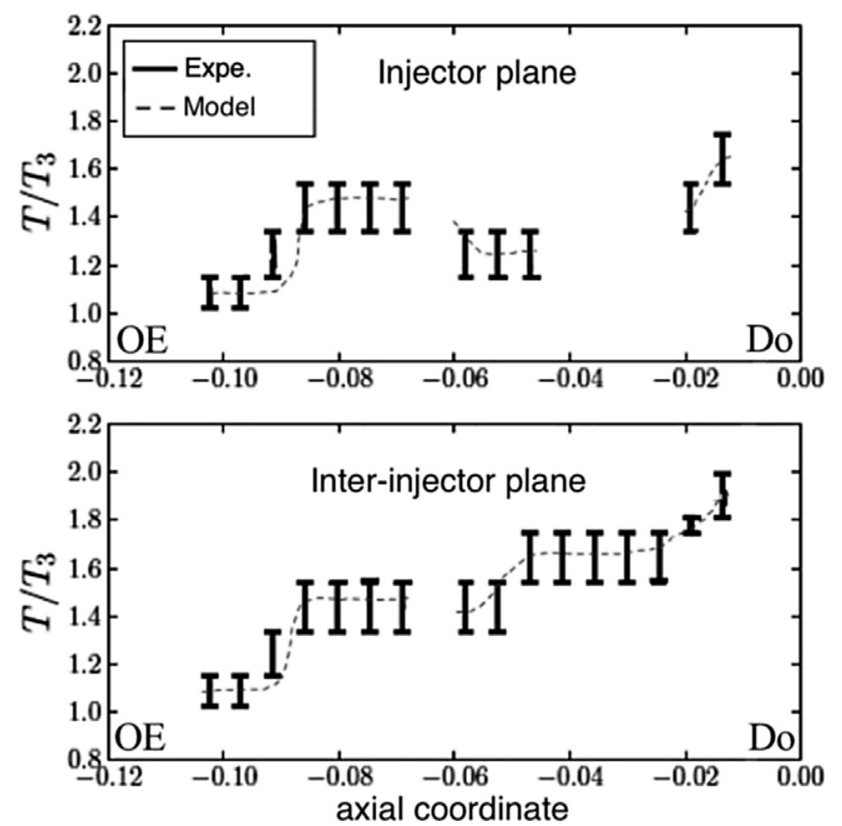

Fig. 21. Comparison between experimental and predicted ( $\theta_{\text {wadl }}^{\text {model }}$ estimator) temperatures on two lines along the engine axis (x) in the injector plane (top) and inter injector plane (bottom). Data is scaled by $T_{3}$ which corresponds to the combustor inlet temperature. to identify possible hot spots to be removed. Note however that radiation is not taken into account, and should smooth the temperature gradients as observed on Berger et al. [10] and Koren et al. [37].

\section{Conclusion}

Two resolved simulations of the flow around a multi-perforated plate were compared; one thermally coupled to the solid plate, the other one being adiabatic. From an aerodynamic point of view, the two simulations lead to very similar solutions. A global energy balance was computed to check quantitatively the accuracy of the numerical database as well as for identifying the main contributions to the phenomena controlling the temperature of the liner. The analysis showed that when the heat flux though the solid is marginal, which is the case for usual engine operating conditions. It is thus possible to assess the wall temperature when using both correlations for heat transfer coefficients and aerodynamic field from adiabatic computation. A robust estimator of the reference temperature $T_{\text {ref }}$ which gives fair result whatever the grid and modeling strategy has been proposed. This estimator corresponds to an integral over the thermal mixing layer. Thanks to the use of a momentum averaging, independent of the grid and modeling strategy, this reference temperature estimator can be used for simulations where the apertures of the perforated plate are not explicitly resolved but the liner is modeled as an homogeneous boundary. This method is affordable for industrial applications, unlike brute force resolved coupled simulations. In the present academical test case, the CPU cost was divided by about two hundred, without considering the savings in terms of meshing time and setup time.

\section{Conflict of interest statement}

The authors declare that they have no conflict of interest.

\section{Acknowledgement}

This work was granted access to the HPC resources of CINES under the allocation 2016-2a6074 made by GENCI. 


\section{References}

[1] H.D. Ammari, N. Hay, D. Lampard, The effect of density ratio on the heat transfer coefficient from a film-cooled flat plate, J. Turbomach. 112 (1990) 444-450.

[2] L. Andrei, A. Andreini, C. Bianchini, G. Caciolli, B. Facchini, L. Mazzei, A. Picchi, F. Turrini, Effusion cooling plates for combustor liners: experimental and numerical investigations on the effect of density ratio, Energy Proc. 45 (2014) 1402-1411.

[3] L. Andrei, A. Andreini, C. Bianchini, B. Facchini, L. Mazzei, Numerical analysis of effusion plates for combustor liners cooling with varying density ratio, in: ASME Turbo Expo 2013: Turbine Technical Conference and Exposition, American Society of Mechanical Engineers, 2013, pp. V03CT17A007V03CT17A007.

[4] A. Andreini, R. Becchi, B. Facchini, A. Picchi, A. Peschiulli, The effect of effusion holes inclination angle on the adiabatic film cooling effectiveness in a threesector gas turbine combustor rig with a realistic swirling flow, Int. J. Therm. Sci. 121 (2017) 75-88.

[5] A. Andreini, G. Caciolli, B. Facchini, L. Tarchi, D. Coutandin, A. Peschiulli, S. Taddei, Density ratio effects on the cooling performances of a combustor liner cooled by a combined slot/effusion system, in: ASME Turbo Expo 2012 Turbine Technical Conference and Exposition, American Society of Mechanical Engineers, 2012, pp. 903-914.

[6] A. Andreini, J.L. Champion, B. Facchini, E. Mercier, M. Surace, Advanced liner cooling numerical analysis for low emission combustors, in: 25th International Congress of the Aeronautical Sciences, 2006.

[7] A. Andreini, R. Da Soghe, B. Facchini, L. Mazzei, S. Colantuoni, F. Turrini, Local source based CFD modeling of effusion cooling holes: validation and application to an actual combustor test case, J. Eng. Gas Turb. Power 136 (1) (2014) 011506.

[8] A. Andreini, B. Facchini, L. Mazzei, L. Bellocci, F. Turrini, Assessment of aerothermal design methodology for effusion cooled lean burn annular combustors, in: ASME Turbo Expo 2014: Turbine Technical Conference and Exposition, American Society of Mechanical Engineers, 2014, pp. V05CT18A012-V05CT18A012.

[9] A. Andreini, B. Facchini, A. Picchi, L. Tarchi, F. Turrini, Experimental and theoretical investigation of thermal effectiveness in multiperforated plates for combustor liner effusion cooling, J. Turbomach. 136 (9) (2014) 091003.

[10] S. Berger, S. Richard, F. Duchaine, G. Staffelbach, L.Y.M. Gicquel, On the sensitivity of a helicopter combustor wall temperature to convective and radiative thermal loads, Appl. Therm. Eng. 103 (2016) 1450-1459.

[11] R. Bizzari, D. Lahbib, A. Dauptain, F. Duchaine, L.Y.M. Gicquel, F. Nicoud, A thickened-hole model for large eddy simulations over multiperforated liners, Flow Turbul. Combust. (2018) 1-13, Online First Articles.

[12] P. Bruel, J.L. Florenciano, Report on the Experimental Velocity Database, with Acoustic Forcing for Multi-Hole plate, Deliverable D3.1.5, European program KIAI <http://www.kiai-project.eu>, 2012.

[13] J.-L. Champion, S. Rouvreau, Plif Analysis of Mixing Phenomena Inside an Effusion Cooling Film, Eurotherm Series, 2002, pp. 193-198.

[14] A.P. Colburn, A method of correlating forced convection heat-transfer data and a comparison with fluid friction. Int. J. Heat Mass Transfer 7 (12) (1964) 1359 1384.

[15] O. Colin, F. Ducros, D. Veynante, T. Poinsot, A thickened flame model for large eddy simulations of turbulent premixed combustion, Phys. Fluids 12 (7) (2000) 1843-1863.

[16] O. Colin, M. Rudgyard, Development of high-order Taylor-Galerkin schemes for unsteady calculations, J. Comput. Phys. 162 (2) (2000) 338-371.

[17] G. Cottin, E. Laroche, N. Savary, P. Millan, Modeling of the heat flux for multihole cooling applications, in: ASME 2011 Turbo Expo: Turbine Technical Conference and Exposition, American Society of Mechanical Engineers, 2011, pp. 1955-1965.

[18] M.E. Crawford, W.M. Kays, R.J. Moffat, Full-coverage film cooling. part I: comparison of heat transfer data for three injection angles, J. Eng. Gas Turb. Power 102 (1980) 1000-1005.

[19] F. Duchaine, A. Corpron, L. Pons, V. Moureau, F. Nicoud, T. Poinsot, Development and assessment of a coupled strategy for conjugate heat transfer with large eddy simulation: application to a cooled turbine blade Int. J. Heat Fluid Flow 30 (2009) 1129-1141.

[20] F. Duchaine, S. Jauré, D. Poitou, E. Quémerais, G. Staffelbach, T. Morel, L. Gicquel, Analysis of high performance conjugate heat transfer with the openpalm coupler, Comput. Sci. Discov. 8 (1) (2015) 015003.

[21] F. Duchaine, N. Maheu, V. Moureau, G. Balarac, S. Moreau, Large-eddy simulation and conjugate heat transfer around a low-mach turbine blade, J. Turbomach. 136 (5) (2014) 051015.

[22] V.L. Eriksen, R.J. Goldstein, Heat transfer and film cooling following injection through inclined circular tubes, J. Heat Trans. 96 (1974) 239-245.

[23] M. Errera, S. Chemin, A fluid-solid thermal coupling applied to an effusion cooling system, in: 34th AIAA Fluid Dynamics Conference and Exhibit, Portland, Oregon, 2004.

[24] J.-L. Florenciano, P. Bruel, LES fluid-solid coupled calculations for the assessment of heat transfer coefficient correlations over multi-perforated walls, Aerosp. Sci. Technol. 53 (2016) 61-73.

[25] J.L. Florenciano, Etude de la réponse d'un écoulement avec transfert pariétal de masse à un forçage acoustique, PhD thesis, Université de Pau, 2013.
[26] B. Franzelli, E. Riber, M. Sanjosé, T. Poinsot, A two-step chemical scheme for Large-Eddy Simulation of kerosene-air flames, Combust. Flame 157 (7) (2010) 1364-1373.

[27] V. Frayssé, L. Giraud, S. Gratton, J. Langou, A set of GMRES routines for real and complex arithmetics on high performance computers, ACM Trans. Math. Softw. (TOMS) 31 (2) (2005) 228-238.

[28] L-Y-M Gicquel, G. Staffelbach, T. Poinsot, Large eddy simulations of gaseous flames in gas turbine combustion chambers, Prog. Energy Combust. Sci. 38 (6) (2012) 782-817.

[29] Ph Grenard, D. Scherrer, A modified wall boundary condition for multiperforated walls, Int. J. Heat Mass Transfer 67 (2013) 16-24.

[30] K.M.B. Gustafsson, Experimental Studies of Effusion Cooling, PhD thesis, Chalmers University of Technology, Goteborg, 2001

[31] C.A. Hale, M.W. Plesniak, S. Ramadhyani, Film cooling effectiveness for short film cooling holes fed by a narrow plenum, J. Turbomach. 122 (2000) 553-557.

[32] J.C. Han, S. Dutta, S. Ekkad, Gas Turbine Heat Transfer and Cooling Technology, CRC Press, 2012.

[33] M.K. Harrington, M.A. McWaters, D.G. Bogard, C.A. Lemmon, K.A. Thole, Fullcoverage film cooling with short normal injection holes, in: ASME TURBOEXPO 2001, 2001-GT-0130, 2001.

[34] S. Jauré, F. Duchaine, G. Staffelbach, L.Y.M. Gicquel, Massively parallel conjugate heat transfer methods relying on large eddy simulation applied to an aeronautical combustor, Comput. Sci. Discov. 6 (1) (2013) 015008.

[35] B. Johnson, K. Zhang, W. Tian, H. Hu, An experimental study of film cooling effectiveness by using PIV and PSP techniques, in: 51st AIAA Aerospace Sciences Meeting, 2013.

[36] V.U. Kakade, S.J. Thorpe, M. Gerendás, Effusion-cooling performance at gas turbine combustor representative flow conditions, in: ASME Turbo Expo 2012: Turbine Technical Conference and Exposition, American Society of Mechanical Engineers, 2012, pp. 857-869.

[37] C. Koren, R. Vicquelin, O. Gicquel, High-fidelity multiphysics simulation of a confined premixed swirling flame combining large-eddy simulation, wall heat conduction and radiative energy transfer, in: ASME Turbo Expo 2017: Turbomachinery Technical Conference and Exposition, American Society of Mechanical Engineers, 2017, pp. V05CT17A010-V05CT17A010.

[38] D. Lahbib, A. Dauptain, F. Duchaine, F. Nicoud, Large eddy simulation of conjugate heat transfer around a multi-perforated plate with deviation, in: ASME Turbo Expo 2016: Turbomachinery Technical Conference and Exposition, American Society of Mechanical Engineers, 2016, pp. V05AT10A002-V05AT10A002.

[39] P.D. Lax, B. Wendroff, Systems of conservation laws, Commun. Pure Appl. Math. 13 (1960) 217-237.

[40] P.V. LeBrocq, B.E. Launder, C.H. Priddin, Discrete hole injection as a means of transpiration cooling; an experimental study, Proc. Instn. Mech. Engrs. 187 (17) (1973) 149-157.

[41] A.H. Lefebvre, Gas Turbines Combustion, Taylor \& Francis, 1999.

[42] B. Leger, P. Miron, J.M. Emidio, Geometric and aero-thermal influences on multiholed plate temperature: application on combustor wall, Int. J. Heat Mass Transfer 46 (7) (2003) 1215-1222.

[43] M. Martiny, A. Schulz, S. Wittig, Full-coverage film cooling investigations: adiabatic wall temperatures and flow visualization, in: ASME paper, (95-WA), 1995.

[44] M. Martiny, A. Schulz, S. Wittig, Mathematical model describing the coupled heat transfer in effusion cooled combustor walls, in: ASME 1997 International Gas Turbine and Aeroengine Congress and Exhibition, American Society of Mechanical Engineers, 1997, pp. V003T09A065-V003T09A065.

[45] Jack D. Mattingly, Elements of Gas Turbine Propulsion, vol. 1, McGraw-Hill Science, Engineering \& Mathematics, 1996.

[46] R.E. Mayle, F.J. Camarata, Multihole cooling effectiveness and heat transfer, J. Heat Trans. 97 (1975) 534-538.

[47] L. Mazzei, A. Andreini, B. Facchini, Assessment of modelling strategies for film cooling, Int. J. Numer. Meth. Heat Fluid Flow 27 (5) (2017) 1118-1127.

[48] L. Mazzei, A. Andreini, B. Facchini, L. Bellocci, A 3d coupled approach for the thermal design of aero-engine combustor liners, in: ASME Turbo Expo 2016: Turbomachinery Technical Conference and Exposition, American Society of Mechanical Engineers, 2016, pp. V05BT17A009-V05BT17A009.

[49] S. Mendez, F. Nicoud, Adiabatic homogeneous model for flow around a multiperforated plate, AIAA J. 46 (10) (2008) 2623-2633.

[50] S. Mendez, F. Nicoud, Large-eddy simulation of a bi-periodic turbulent flow with effusion, J. Fluid Mech. 598 (2008) 27-65.

[51] D.E. Metzger, D.I. Takeuchi, P.A. Kuenstler, Effectiveness and heat transfer with full-coverage film-cooling, in: ASME Paper 73-GT-18, 1973.

[52] B. Michel, P. Gajan, A. Strzelecki, A. Kourta, H. Boisson, Simulation numérique d'une zone d'injection pariétale pour une chambre de combustion de turbomachine, in: 18ème Congrès Français de Mécanique. Grenoble, août 2007, 2007.

[53] P. Miron, C. Bérat, V. Sabelnikov, Effect of blowing rate on the film cooling coverage on a multi-holed plate: application on combustor walls, in: Eighth International Conference on Heat Transfer, Lisbon, Portugal, 2004.

[54] A. Most, N. Savary, C. Berat, Reactive flow modeling of a combustion chamber with a multiperforated liner, in: 43rd AIAA/ASME/SAE/ASEE Joint Propulsion Conference \& Exhibit, 2007, p. 5003.

[55] E. Motheau, T. Lederlin, J.-L. Florenciano, P. Bruel, LES investigation of the flow through an effusion-cooled aeronautical combustor model, Flow, Turbul. Combust. 88 (1-2) (2012) 169-189. 
[56] F. Nicoud, F. Ducros, Subgrid-scale stress modelling based on the square of the velocity gradient, Flow, Turbul. Combust. 62 (3) (1999) 183-200.

[57] F. Nicoud, H. Toda, O. Cabrit, S. Bose, J. Lee, Using singular values to build a subgrid-scale model for large eddy simulations, Phys. Fluids 23 (8) (2011) 085106.

[58] B. Petre, E. Dorignac, J.J. Vullierme, Study of the influence of the number of holes rows on the convective heat transfer in the case of full coverage film cooling: Etude de l'influence du nombre de rangées de trous sur les échanges convectifs dans le cas du refroidissement par multiperforation, Int. J. Heat Mass Tran., 0017-9310 46 (18) (2003) 3477-3496, https://doi.org/10.1016/ S0017-9310(03)00126-1.

[59] J.R. Pietrzyk, D.G. Bogard, M.E. Crawford, Hydrodynamic measurements of jets in crossflow for gas turbine film cooling applications, J. Turbomach. 111 (1989) $139-145$.

[60] T. Poinsot, S. Lele, Boundary conditions for direct simulations of compressible viscous flows, J. Comput. Phys. 101 (1) (1992) 104-129.

[61] C. Priere, L.Y.M. Gicquel, P. Kaufmann, W. Krebs, T. Poinsot, Large eddy simulation predictions of mixing enhancement for jets in cross-flows, J. Turbul. 5 (005) (2004) 1-24.

[62] S. Rouvreau, Etude expérimentale de la structure moyenne et instantanée d'un film produit par une zone multiperforée sur une paroi plane, Phd thesis, ENSMA, 2001.

[63] N. Savary, B. Michel, P. Gajan, Validation and benefits of a homogeneous effusion cooling model for combustor RANS simulations, in: 47th AIAA
Aerospace Sciences Meeting including The New Horizons Forum and Aerospace Exposition, 2009, p. 1377.

[64] J.J. Scrittore, K.A. Thole, S.W. Burd, Investigation of velocity profiles for effusion cooling of a combustor liner, J. Turbomach. 129 (2007) 518-526.

[65] A.K. Sinha, D.G. Bogard, M.E. Crawford, Film-cooling effectiveness downstrean of a single row of holes with variable density ratio, J. Turbomach. 113 (1991) 442-449.

[66] J. Smagorinsky, General circulation experiments with the primitive equations: 1. The basic experiment, Mon. Weath. Rev, 91 (1963) 99-164.

[67] H. Baya Toda, O. Cabrit, K. Truffin, G. Bruneaux, F. Nicoud, Assessment of subgrid-scale models with a large-eddy simulation-dedicated experimental database: the pulsatile impinging jet in turbulent cross-flow, Phys. Fluids 26 (7) (2014) 075108.

[68] S. Voigt, B. Noll, M. Aigner, Development of a macroscopic CFD model for effusion cooling applications, in: ASME Turbo Expo 2012: Turbine Technical Conference and Exposition, American Society of Mechanical Engineers, 2012. pp. $1235-1243$.

[69] F. Zhong, G. Brown, Experimental study of multi-hole cooling for integrallywoven, ceramic matrix composite walls for gas turbine applications, Int. J. Heat Mass Transfer 52 (3) (2009) 971-985.

[70] F. Zhong, G.L. Brown, A 3-dimensional, coupled, DNS, heat transfer model and solution for multi-hole cooling, Int. J. Heat Mass Transfer 50 (2007) 1328 1343. 